\title{
A Hidden Danger to Our Children's Classrooms within Educational Leadership \& Peering Practices
}

http://doi.org/10.21272/bel.4(4).28-55.2020

\author{
Antony D. Miller, \\ Dr., $\mathrm{PhD}$ in Educational Leadership; International Educational Advisor, Philosopher, Fellow to the Chartered \\ College of Teaching UK, University Contributor and Debater, Ulaanbaatar, Mongolia
}

\begin{abstract}
This comprehensive body of research is an empirical attempt to purposely examine if our offspring: children, teenagers to adulthood, [Treasures] are, being subjected to political interference [indoctrination] within their respected theatres of education, and therefore, be a negative impact for their respective future endeavours, emanating from the West and quickly heading into cultures of the Eastern regions demographically. Besides, the research has included how it has impacted the current stasis in the Western educational system? The sample consists of the history involved, current statistics from global sourcing methodology, biases notated on within the political equation, and how has this has affected business. Both quantitative and qualitative analysis models are illustrated within extensivity. Two new philosophies are being introduced, named "Miller's Social Cultivation Paradox SCP and the second being Eight Dominions to Dystopianism. The data therein would confirm research findings within empirical validity via standard error mean for difference projections within the subject matter's hypothesis, thus, subsequently determine data mining findings. The reader ought to discern, then consider from this paper, if our treasures are in danger within their learning domains, or is this current pedagogical practice in kindergartens, K-12 schools, and higher institutions of learning, are indeed acceptable to both academics and parents alike, for the years to come? Wherefore, within the subject hypothesis - have teaching methodologies changed for the worst or the better? The premise of this investigation and resulting study, has attempted to be simplified and unambiguous, and to expose a 21 st century's western education ideological system, and heretofore emanating from the early years' classrooms, percolating through both high schools to higher educational institutions of note. Moreover, the exposition of the false unproven narratives on global warming, being enforced onto our children via their educators' classroom practice, devoid of empirical facts, inclusive of how public leadership and policy, have been both physically and emotionally endangers our school-aged children. Thus, culminating in being shown that a politically culturally biased teaching method over decades, has indeed infiltrated student theatres of learning, resulting in alumni [treasures] eventual disaffection with their own respective country, family values, inclusive of law and order. This body of research would illustrate the possible future outcomes and advisories of vigilance, for both parents and researchers concerned.
\end{abstract}

Keywords: Education, Globalization, Society, Methodology, Public Policy, Materials, Faculty, Race, Ideology, Parent, Treasures, (Children) Left-Leaning, Global Warming and Misinformation.

JEL Classification: I21, I23, I24, Q54.

This work is licensed under a Creative Commons Attribution 4.0 International License

Cite as: Miller, A.D., (2020). A Hidden Danger to our Children's Classrooms within Educational Leadership \& Peering Practices. Business Ethics and Leadership, 4(4), 28-55. http://doi.org/10.21272/bel.4(4).28-55.2020.

(C) The Author, 2020. This article is published with open access at Sumy State University.

\section{Introduction}

Having taught in many capacities within schools and university service inclusive of the private sector for nearly over thirty years, it has been gradually coming to one's attention that the young generations post 1989 have potentially been targeted and challenged by certain political ideologies at a very young age. This possible cultural instability, which has led to the encapsulation of probable cultural re-engineering, has progressed from grade 7 K-12 studies within university lectures via its majority left-leaning-biased academic faculty. Once, there was a thought of a mere phase of modernity in twenty-first-century educational practice; however, this was the deliberate false narrative that parents ought to believe. As the three decades have moved through time epochally, it has become clear that educational classroom methodology could be something much more that we were once told to believe as teaching practitioners. I once recalled a quote from the book "The Misquotable": 
Education without values, as useful as it is, seems rather to make man a cleverer devil (Lewis, C.S. et al., 2018). He was concentrating on the factual elements, and in so drafting, he stated in which education without any values made a person smarter, but devoid of morality, this person might resemble the Devil him or herself. A comprehensive study was needed to be conducted by oneself to delineate if our "Treasures" were/are being used as pawns upon a proverbial chessboard, further a more systemic goal for political purposes, and change our respective societies. This paper attempts to outline the hidden dangers within today's Western teaching practice methodology and show how it has become virulent in theatres of Higher Education, but inclusive within $\mathrm{K}$ thru 12 also. Besides, there will be an attempt to delineate the doctrinal legacy from many years and how dangerous it has become in the modern era. We will venture on a journey together with absolute clarity history, cultural alteration, dissention of a nation or nations, and how a western generational majority below 45 has accepted law and disorder as a right? The very same individuals are willing to take an ideology, which has failed throughout history worldwide. It begs the question how could they ever pay a contribution to society without a character and devoid of morals? Then only to merely destroy it, and how could these purveyors of historically unproven, unworkable notions, be a trusted practitioner within the teaching profession and presiding over our treasures in their classrooms? There indeed lay the question and the thesis of this paper.

\section{Methodology}

As replicated from this paper's abstract, this investigation's premise and therefore the study is unambiguous and straightforward without political biases; to expose a 21st Century's Western education ideological system, emanating from early years classrooms, permeating through to both high school and higher educational institutions. Furthermore, it will be shown that a politically cultural biased teaching method, over decades, has indeed influenced student theatres of learning with harmful effects. Thus, resulting in the alumni's [treasures] disaffection with their respective country. Unfortunately, it is inclusive of the disrespecting of law and order, and this heinous ideology, has attempted to procreate a body of people [graduates] by progressive university faculty cohorts, to both reject their given history and a society's way of life. Over a four-year changeable cycle, this body of research had researched many samples sets of which exemplified current teaching practices, ensuing from the geographical West, and how specific entities are spreading this philosophical contagion to the East - thus, the world. Consequently, many well-known modern literature works referring to history have been both notated and cited from highly respected authors and academics alike, to aid and with sources of defense, to facilitate this constructive, coherent body of work. Primarily, the United States and the United Kingdom have been implicated in this study of furtherance, with the European Union States' additional inclusivity. Therefore, data collection has been attributed to real dynamics from international NGOs and governmental departments of statistics. Finally, the barometer of education depravity has been afforded to this study, via the respectable source outlets that had enabled the tabulations asserted within collaborated accuracy, in tune with statistical method deviations with delineation.

\section{Literature Review}

This research has uncovered data that strongly suggested that both K-12 and higher education have attempted (with relative success) to navigate our children's inclusive of teenagers through a myriad of unsavory in-house Neo-Maoist and Marxist indoctrination. It could inevitably forge a new workforce of little strength, less debating skills devalued creativity in ideals, and a willingness to further the inclined destruction of their respective societies therein. Additionally, being naively active, participating in a cultural demise, and merely initiating a reality of lawlessness, a void for intellectual thought/construct, realize the ramifications of such a fervent ideology. Moreover, the United Kingdom's liberal-leaning newspaper The Guardian, once stated that: The West has assumed that Maoism, akin to Soviet communism, has been left in the dust (Lovell, 2019). The article entitled: Maoism marches on the revolutionary idea that still shapes the world was an essential body of work to permit this research study to be written within a non-bias contextual overview, thus, the mere gathering of the facts methodologically, within data gathering protocols. The sources of data collection are variable sources within both education, history and economic development, and additions from highly renowned academics of given repute. To retain one's objectivity within this research body, there is a synthesis of all correlated data from western nations, primarily the USA and the European Union, onto plotting a course eastward with the and the addition of comparative elements attributed to other countries similar in demography, geographical location, and asymmetrical democracies.

Teacher Education and the Outcomes for our Children in their Institutions of Instruction. Today's western education system has been displaying one-sided biases combined with a program of both the re-modeling and indoctrination of societies via our treasures or children, within their schools, by their very own younger inexperienced teaching faculty. If we were to begin with K-12 education, both parents and school governing bodies have displayed naivety to curricula and individual teacher lesson plans that have been tainted with 
suspicious political subject reading materials opposed to the students' own 'national histories, inclusive of guilt being placed upon them from years 3 to 6 initially. This is a dangerous neo-liberal policy to merely polarize global society, rather than the nurturing and development of their character. Besides these, the heads of prominent teacher unions are very much engaged in a once upon a time Maoist/Marxist ideology. In times past, the very fabric to the subject of history, was a class that children delineate the present as a comparative to the past. It has seemed that faculty members are re-creating history as a form of "redesign" for a future progressive societal change. There is both good and bad history apropos to the world. However, it is also taught to pupils; for them to experience what has been amended from uncertainty and what the founders of a nation had created by their extolling of a state's laws and constitutional edicts. The pupils' preparation in their academic journey would engage in courses such as civics for clarification. Contra to this, untruths are being presented to pupils rather than fact in the historical domain. Are these teachers of today selling their selfindulgent delusions via the classroom instead of peering into a mirror to repair their very own failings, misgivings, and lack of accomplishments? It is the second premise of investigation in this body of research. More importantly, this is a guide for academics and parents alike - to eventually research more into their children's' theatres of education and how their curriculum is being prepared and taught in the West. Finally, to confirm if these western practices have been steering themselves in an eastward direction, conversely, influencing eastern nations? Allow me to indulge the audience on one subject being taught within schools today, from years 6 to 7, K-12. There has been much debate on non-Caucasian lives and the guilt complex being presented by faculty members onto our treasures. Namely, books from Marxism, Slavery, Racism and being an effective protester are taught/professed by English-History Teachers and Sociology Practitioners. A sample of class core-reading materials for which are being enforced upon our school-aged children follows a quote regaled from memory "Parents and other caregivers are seeking resources to help them hold children through the current, terrible wave of racialized violence, which is exacerbated by the tensions and vulnerabilities" (Allen et al., 2020). These so-called modern educators and advisors compiled a compendium of publications for our treasures school district curriculum, Table.1.

Table 1. Compliments of 20 Picture Books for 2020: Readings to Embrace Race, Provide Solace \& Do Good

\begin{tabular}{|c|c|c|c|}
\hline Titles & Authors & Published & Subject Matters \\
\hline A Big Bed for Little Snow & Grace Lin, Little Brown & 2019 & To promote Chinese characters \\
\hline Black is a Rainbow Color & Angela Joy & 2020 & Black Americans \& Social Justice \\
\hline A Girl Like Me & Angela Johnson & 2020 & Diverse children \& their humanity \\
\hline Going Home with daddy & Kelly Starling Lyons & 2019 & Multigenerational Black Life \\
\hline Hammering for Freedom & Rita Lorraine Hubbard & 2019 & A blacksmith saving to buy freedom \\
\hline
\end{tabular}

Source: Allen, A. (2020)

It is clear from the above publications that one race has been singled-out to be manipulated or to be forced with biasness onto multi-ethnic school-aged children. Resulting, in the negation of other racial histories such as Hispanic, countries of Islam and White, thus, to make these minorities the main actors for black suppression. In short, being a case-in-point for the politicization of our child's classrooms. The dangers are clear, do black lives and their culture matter, or do all lives and all cultures matter? The latter instills a multicultural nation; however, other countries that are not multicultural and possess their ways of life and existence are in an attempt being forced into accepting such a school system that encompasses societal transformation or societal polarization. Other instances of school reading materials within lesson planning are also tabulated in (Table 2).

Table 2. Sample of Books Being Read by Elementary Pupils and the Recommended Age Ranges

\begin{tabular}{|c|c|c|c|}
\hline Titles & Authors & Rec. Age Group & Subject Matters \\
\hline Henry's Freedom Box & Ellen Levine & $4-8$ & Boy Slave Escapes to Philadelphia \\
\hline So Tall Within & Gary D. Schmidt & $4-8$ & Black American Civil Rights \\
\hline The Bell Rang & James E. Ransome & $4-8$ & Young Black Slave Girl \\
\hline
\end{tabular}

Source: Allen, A. (2020)

There are hundreds of books on this theme within the school elementary system today in both the USA and the United Kingdom, sanctioned by their respective educational governing bodies. As parents, we must ask ourselves the fundamental question; why has social justice in countries that bare no relation to black history, being forced to accept that black slavery was wrongful in action? In the USA and UK, Caucasian children are hypnotized into guilt for the slave traders' activities. We also must question ourselves as parents and educators alike; has this form of rhetoric, social school intimidation and an attempt to destroy civil society originate from history itself? Why have black Slavery issues been brought to the fore in classrooms, even though they cited as misleading and the historical data refutes the narratives?

Delineation I. To see the white race is only accountable for slavery is incorrect in a parse in time historically. Facts: Blacks were slave owners too. In a famous court ruling in 1655, Mr. Anthony Johnson, [Black 
Businessman] was granted extended ownership of an African Slave, John Casor, to be retained indefinitely, yet, this has not been cited in schools. Besides, further evidence of the one-sided misnomer of Black Slavery by White slavers was illustrated in a book by Dr. Robert Davis -professor of history at Ohio State University. He has researched slavery in-depth, which led to his publication "Christian Slaves, Muslim Masters: White Slavery in the Mediterranean, the Barbary Coast, and Italy, 1500-1800". In the 300 stated years, over one million to 1.25 million white European Christians were forced into slavery between 1530 to 1780 . According to Davis, the Atlantic Slave Trade was much more extensive. However, for present-day educators, to apportion the blame for all slavery in their vague reasoning attempts is inaccurate. Moreover, the evidence suggests it is forced upon school-aged children to persuade them that their respective white races were solely to blame for Black Slavery. Nevertheless, within the realms of intellect, it is clear from history that white skinned people were enslaved. Yet, there are no reading materials in today's schools that depict any balance to this ideological argument. Furthermore, the epoch that Davis had studied and described exhaustively could have been the time that religion, race, and ethnicity determined who became slaves. Even Ireland, Iceland, and the United Kingdom succumbed to the Corsairs [North African Pirates] from predominantly Tunisia, Morocco and Algeria. (Davis, 2003). Once an enslaved African, Equus Anna remarked: When you make men slaves, you deprive them of half their virtue, you set them in your own conduct an example of fraud, rapine, and cruelty, and compel them to live with you in a state of war.

Ideology to History: Whence it Came. We should ask, inclusive of intellectual thought, to ascertain from where has this change within western teaching methodology/practice or ideology derived? As educational practitioners, scientists, or parents, Antonio Gramsci (1891-1937) of Sardinia was an Italian Marxist theorist, socialist/communist on intellectual thought and politician. He wrote on political theory, sociology and occasionally on linguistics. Having influences as Karl Marx, Vladimir Lenin, and Niccolò Machiavelli, he believed that as the proletariat masses could not be comprised of the working class, so his writings inferred that philosophy had to become more radical; by the installation of professors within universities to effect change in courses taught, the redesigning of curricula and departments therein. Subsequently, to politicize the departments. It would be a protagonist (indoctrination) in the form of cultural brainwashing of the students within these said departments and university faculties. Gramsci once stated: The challenge of modernity is to live without illusions and without becoming disillusioned. It is contested by me, like Gramsci, that a man of intellect indeed possessed illusions that were both delusional and harmful to youth development. Therefore, it was found empirically within this study. David Horowitz, in his publication entitled: How Radical Professors at America's Top Colleges, Indoctrinate Students and Undermine Our Democracy (2009) in the discussion, was very informative and unambiguous to what was occurring within schools of thought in the West to-date. In his research, Horowitz discovered that not only many university campuses had increase d in radical neoliberal and enhanced activist faculty but had also influenced both Presidents and Deans alike by introducing progressive faculty-prescribed courses and their curricula. This study uncovered and disseminated that newly appointed professors enabled between ten to thirty-thousand methods to aid in a Marxist-Maoist ideology. The research also discusses how open these "extremist left-leaned" faculty members have been changing mindsets to create a new breed of society via the student body. That is why controversial courses are defined as Gender Studies, Ernesto "Che" Guevara and revolutionary or, for a better term, misanthropic directional platformed subject matters, therefore, destabilize our alumni and use them to reinvent a future civilization. We must recall that these distinguished academics have been labeled anti-capitalism, anti-free market, anti-gender born at birth, anti-heterosexual, anti-bordered countries pro-polysexualities. As both academics' and parents' question, we must be this a stable state of play, which could enhance our treasures [youth] for society, or will our child's respective future be endangered compared to the past's traditional educational governance?

The aim of these progressive educators in our volatile society is to remove the queen from the beehive. Is it tangible that there is a hubristic body of people who wish to redefine nature's very fabric within society itself? Are we accepting the removal of all that has come into being, throughout the generations, inclusive of human evolution within the basic laws whence it came, and to adhere to, and to somewhat cherish? I leave you with this thought, some nations keep a distance from this form of behaviour and destabilize ideological reforms, therefore retaining the sovereign dignity of their landmass and the culture retention of its population. These are former communist countries and formerly of the Eastern bloc. These Eastern European nations were subjected to tyranny for decades under the Union of Soviet Socialist Republics (USSR); thus, they do not wish to experience the second chapter of Cultural Socialism and for their respective identities to be eroded once more. Yet, on this occasion, however, countries are being been canvassed by the Western activist teachers who are covertly working as faculty members within their international schools, state schools via NGOs, universities and other programs, to influence a nation's children upon their classrooms merely since they are more financially suggestive to rhetoric, albeit, good or bad. Noted is Ukraine's case and how it was transformed 
in western orientation by NGOs, Social Media and western educators within the cities. This ideological method will be clearly outlined within the next paragraph, referring to the Frankfurt School and Lukács, G. (1919).

It may be asked by yourself, where did this neo-liberal rhetoric and its narrative for Political Correctness derive? Firstly, if we were to recollect, that political correctness "PC" as a weapon, really originated in 1922 from the Institute for Social Research at the University of Frankfurt or the so-coined "The Frankfurt School." Yes, nearly a century ago. One of its Marxist theorists that emanated from this social school of thought noted alumnus György Lukács tried to introduce Cultural Terrorism upon his return to his native land Hungary, with the dialectic of undermining the unity of the family and the targeting of children as they were at an age to be more suggestive more than adults sound familiar? Moreover, Marxism was combined with Freudian theory, especially psycho-analytics. Since world war one until the 1930s, a new form of Marxism was being established at this said school. A paper written via this so-called school of liberal thought entitled "The Genesis of Cultural Theory" had the essence of this similar ideology, which was simple but effective. If we were to be asked the question, what is the theory? The Frankfurt school's answer would be the theory to criticize. We have already experienced and faced such rhetoric in the West. It would be the divisive criticism used to bring down Western society's very fabric to exemplify this. By the 1960s, the working class/blue collar populous had still failed to conform to this newly found liberal ideology, so a surrogate community had to be found. Despite this setback, Marcuse, the social theorist, and a conduit for more left-leaning ideas, wrote: "Eros and Civilization" (Marcuse, 1955). In fact, in the late 1960s, that had forged the genesis for the sexual revolution apart from being philosophical i.e., opposition groups rose with his notion for a sexual liberation that eventually morphed into the LGBT movement of the present. Today, Critical Race Theory is the basis for classes in black studies, women's studies, and many more that have infiltrated western liberal arts university campuses. In other words, as was once defined by me as "A collage of insanity."

That above was disclosed due to the wish to convey and depict that this form of brainwashing or this neomethodology would be hard to eradicate unless a nation has not conformed to this utopian dictum -by disallowing radical insurgents (unrelated culturally) through their respective frontiers. Furthermore, this form of Marxism has gone through a series of improvements, modifications and manifestations over these last eight decades and has been a red goblet filled with potential societal destruction. This ideological form of the manifesto has been furthering both the battles and the war via societal, cultural, and incentivized behavioral change; from school teachers to university professors, they have an unchallenged avenue to corrupt our future generations further. Tactical strategies exemplifying these would encounter freedom of speech, revising a dictionary or thesaurus and the shaming of conservative thought, which has led to lessening intellectual debate and freedom within the creativity of thought. Statistically speaking, from the 1960s to the late 1970s, university faculty comprised a forty percentile of conservatives and a sixty percent from the left, as it was then Centreleft/Traditional Liberals and Centre Right.

In the present day, professors over the age of 55 outnumber conservative professors by ten to one. Faculty under the age of 36 surpass conservatives by twenty to one. Even commencement speakers of whom being invited to college events, the conservative speakers nonetheless, were outnumbered five to one. If we were to peer at the Western universities (State or Private) of the current day, we would have seen that university campuses have become more left-wing politically. "In 1994, the share of those with a graduate education who held consistently liberal views was 7 percent (compared to today's 31 percent). The share with mostly or consistently liberal views was 31 percent (compared to today's 54 percent) (Jaschik, 2016). The above mentioned was researched in 2016 and has arisen considerately more in 2020 . Therefore, the higher the alumni's grades become, the more Marxist and Maoist in political ideology they have attained in mindset. It is all attributed to the overwhelming neo-liberal faculty members [not traditional liberals] that had once presided in schools of thought. In brief, these new-age teaching faculty members in K-12 and higher education have been endangering our treasures [children] by removing traditional teaching methodology. Case-in-point, being that the common classroom practice today is instead of teaching students, and school pupils being shown "How to Learn", they are being taught "What to Learn," A one-directional form of classroom peer management, which could only be perceived as school totalitarianism. The data sets involved could not be described within a politically neutral framework, as it was so overwhelming to one side of the political aisle or spectrum within the standard of error calculus.

Not only School Marxism, but Maoism. To further elucidate what is occurring in Western school systems, it has been spreading dangerously throughout the world. Marxist ideology within these so-entitled educators is a misnomer as witnessed in Asia in the past years. Western teachers are now practicing in schools and professing their political agendas upon their students and ostracizing notable leaders of conservative-led nations. Conversely, we must recall that politics has no place in any classroom. Moreover, teachers have already been caught on the platform "Zoom" via remote/virtual classes by the pupils' parents, citing left-wing 
political rants and inappropriate behaviour from these online class teachers. All parents must be asked once more; how could this be occurring in our child's classroom? School teachers in their respective classrooms negated clarity within any given nations' 'history'. Therefore, it has been brought into question. It has been concluded from this body of research that apart from the witnessing of educators personally, both Western School teachers and University faculty below the age of 45 are most of the sole professing or promotion/propaganda of a radical classroom ideology. Both Central and South Asian nations have succumbed to western school teachers being unchecked regarding their respective classroom politics: Hong Kong, Mongolia, Kazakhstan, to Cambodia have been subjected to these younger radical teachers within their respective private schools. Before these nations being culturally invaded in the early 2000s, Turkey and as it is today, its students have been under the influence by a form of both Marxist and Maoist classroom indoctrination by mainly British, Australian and US educators of limited class time experience -yet again, usually under the age of 45 . The nations above have already experienced this enforced socialism placed upon their school pupils. These educators are social-oriented moralists and try to pervade their message in a foreign classroom or a foreign theatre, albeit of higher education. They have displayed no form of morality upon their student bodies, hence, applying politics within the ignorance of their classes. The signs are easily displayed when interviewing a younger teacher of the West these days. From questioning, their radicalism is depicted from their attire noticeably. Non-Conservative nor formal dress code is applied. Personal grooming is, indeed, lacking. Besides, they are not excellent listeners and believe in their ideology. Consequently, they are very opinionated and ignore debate and criticism, which does not encapsulate rational thought. Unfortunately, the English Language Teaching Profession with practicing western teachers presiding in foreign countries has been badly affected by this form of a left-wing mantra within the past 25 years. So much so that the entire profession's integrity and credibility have been brought into question. The final indications are Zero classroom management, what to learn, not how to learn philosophy, devoid of discipline both in or out of class, and to try to impart their ideologies onto others with neither substantive facts nor evidence. Thus, to all parents, please be careful of the educator being hired for your child's school.

Why Maoism apart from Marxist theorizing? The recent events illustrated both in the U.K. and chronicled in the United States on the utter destruction of historical Memoria like statues and other effigies have exposed not only to Marxism ideals but Maoism. This restructured method is a societal revolution within an equation of teaching practice in the litany of schools' type of child manipulation. "Revolutionary zeal, not weaponry, was the decisive factor" (Lovell, 2019). The weapons are directed toward the educational theatres themselves. Hollywood and the media have been decisive factors in promoting this virulent tumor, which has metastasized not only throughout western education and its faculty but also progressing worldwide as an indoctrination odyssey; as many have named, Utopian. "Sympathy with Mao's China merged with outrage over the mistreatment of American "internal colonies" - black, Latin and Asian American. Impressed by Mao's denunciations of U.S. foreign policy and expressions of solidarity with black rights, the militant wing of the African American liberation movement channeled Mao's ideas to challenge the white American ruling establishment" (Lovell, 2019).

Does this sound familiar to the present day's rhetoric -both in U.S. politics and the effects within our respective educational institutions? It is not an original ideology, but merely a continuance of a century's old agenda to circumvent the world as we know it. Unfortunately, it has involved the systemic brainwashing of our children at school to decide the political outcomes of our cultures' well-being. One feels that we have made a connection or relevance to Maoism about our respective educational plight. As postulated by Cole M. (2019), "What was once a dangerous trend only in Christian universities has seeped down into private Christian academies. It has been done through the introduction of critical race theory into the middle and upper schools. "Woke" white and black teachers fancy themselves social justice warriors. Critical race theory is rooted in cultural Marxism; its purpose to divide the world into white oppressors and non-white victims. It uses personal narratives of marginalized minority "victim" groups (black, Hispanic, female, and homosexuals) as irrefutable evidence of the dishonesty of their mostly white heterosexual oppressors." It is another indication within a citation to illustrate further that our school systems are being corrupted by a spin-off Marxist aspiration to socialize the world via our "Treasures" or preferred conduit, to ferment ideology rather than providing a worthwhile traditional education. If we were to refer to "Das Kapital" by Karl Marx, he theorized that: Education is free. Freedom of education shall be enjoyed under the condition fixed by law and under the state's supreme control. It indeed admonishes capitalism, not only in education itself but within the private school system. It has been noted: about 18 percent of social scientists in the United States self-identify as Marxists, compared to only about 5 percent who identify as conservatives, Dunn and Shields reported. (Spencer, 2016). However, returning to Maoism, if we refer to history: So, began the Cultural Revolution, the terrible, blood-stained period in the late 1960s, when mobs of self-appointed 'Red Guards' rampaged across China. For ten years, Chairman Mao's followers burned books, tore down statues, and murdered millions loyal to the 'Four Olds' - old 
ideas, culture, customs and habits, Sandbrook, D. (2020). This is one both referring to, and relating to the events of the summer of 2020 , connecting the burning of effigies and the attempted removal of factual history within western states and schools alike. It is evident that this neo-liberal ideology is both related to both Marxism and Maoism. Therefore, it has no place within our schools -inclusive of reading materials therein. The above article from Sandbrook describes the dangers we are facing for our children's educational future. As the book burning decade of China's Chairman Mao in the 1960s, were a bloody affair, to say the least, and not to be envisaged as an appropriate part of a school curriculum thereof.

Teacher Training Dangers for Our Children's Psychological Development. If we were to delve further into today's licensed teacher training, it has been noted that Critical Race Theory in the United States has been dominant in Teacher Training Practice. It has been discovered that there were immense floors or failings within teacher methodological training. Namely, Epoch Education USA is one of many contractors that engage with future teaching practitioners. An excerpt from this company's reading package has been attached to this paper within the realm of coherence, as the intellectual to decern what is taught or furthered in political ideology, and to deduce the mindset of a new teacher coming from a western educational framework.

Critical Race Theory's Ideology Quote. "Critical race theory is grounded in the Civil Rights Movement and from its beginning has focused on social justice, liberation, and economic empowerment (Tate, 1997). Its origins can be traced to the critical legal studies movement of the 1970s (Brayboy, 2005; Lynn, Yosso, Solo rzano, \& Parker, 2002). Critical race theory emerged from critical legal studies because of the latter's inability to address People of Color's struggles (Brown \& Jackson, 2013; Solo rzano \& Yosso, 2001; Stanley, 2006; Taylor, 2009; Yosso, 2005). Thus, critical race theory emerged as a form of legal scholarship that sought to understand how White supremacy and its oppression of People of Color had been established and perpetuated. In doing so, race and racism was placed at the center of scholarship and analysis by focusing on such issues as affirmative action, racial districting, campus speech codes, and the disproportionate sentencing of People of Color in the U.S. criminal justice system (Lynn \& Adams, 2002; Taylor, 1998). - Critical Race Theory in Higher Education: 20 Years of Theoretical and Research Innovations, Dorian L. McCoy, and Dirk $J$. Rodricks. As we have read, this form of propagandized literature is within $80 \%$ of your new teachers' mindset, planning and teaching methodology.

Today's Student School Teacher Training - Methods and Syllabi. A paper entitled 'Skewed Prospective' published by Harvard's 'Education Next' website, illustrated what is being professed within well-known institutions of thought in the United States of America. The following observations were cited: Reading material was deemed objective by the study; for example, usual readings in the Socratic methods discussed for over two millennia were omitted. Stanford University was a case in point. The Socratic insights and dialogues were too taxing for these students. Additionally, a close method of instruction had been preferable, like reading Dewey, for instance. In contrast, the ridiculous part of an absurd mandated course read has become one without intellectual thought. The said university's course literature for student teachers is written by authors who are predominantly American, preferably within an international scoping prospective. The reading material was published within only the past thirty years, and there was no publication written before 1974. In short, Europe, Asia, Africa were not even mentioned. Thus, one of the USA's top universities sought a balanced approach, to teacher training, due to feelings/emotions and political opinion or persuasion. The research has also cited that there had been an effort to skew the shape of teacher judgment to "fundamental" world views. We ought to question the adjective "Fundamental" in this form.

Delineation II. One can see that the goals of this newly attached rhetoric in our educational systems are, in fact, not new at all. It is a former version of cultural socialism and agricultural revolution - re-vamped to serve its original purpose of global dominance by the indoctrination of the "young", i.e., to lay the foundation of future populations as these treasures of society are indeed susceptible to the infantile rantings of a younger politicized western schoolteacher. It will be known that these aforementioned young treasures will be a prelude to a new tyrannical epoch within their own respective countries. They will mature into a dominant force, which in turn could become Statesmen and Stateswomen. Their over-socialist mindset or intellectual thought would then affect the professions: the military, the police, and their educational governance and, more importantly, the decision-making quality involved within key policy arguments for domestic/global relations within economics and conflicts of war. Without any form of ambiguity, at the Western schools, one postulates that children are shown what to learn rather than how to learn. In light of these developments that have spanned predominantly since the late nineteen eighties, one has devised a diagrammatic preview named Miller's Social Cultivation Paradox (Figure 1), to simplify what is indeed occurring in the present-day western educational system. 


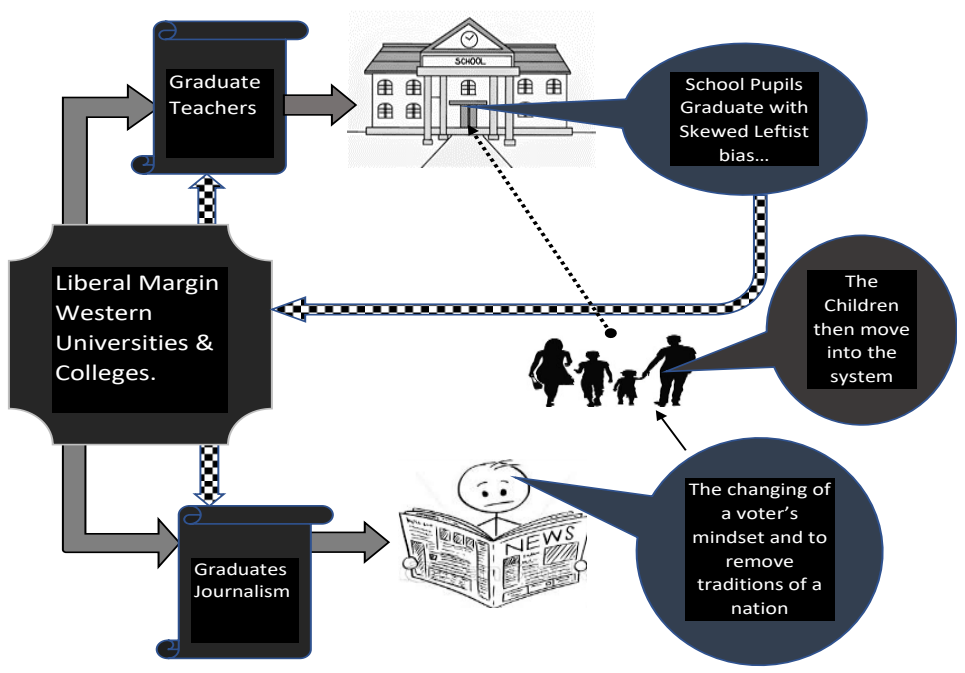

Figure 1. Miller's Social Cultivation Paradox SCP

Source: Table 1. and Table 2. p.30, originated by author

The diagrammatic, Miller's Social Cultivation Paradox SCP demonstrates that two main professions that have been cited, which have a significant bearing on society, cyclical within its concept. Successive socialist governments have finally succeeded within the former Antonio Gramsci's model p.8, of infinite domination of higher education. This procedural paradoxical result outcomes, illustrate that most graduates from the mentioned university cultivate the student body into a one-sided socialist mindset bordering communism. Later as alumni, take their newly adopted left-leaning ideology into their respective professions - namely, in this case, both Journalism/Media and Teaching. Following schooling from as young as elementary to high school graduation, most of the pupils' ways of thinking have already been changed by their indoctrinating class teachers, compared to their parents' original traditions. Therefore, certain mindsets toward Marriage, Birth Control, LGBTQ issues, and Religious doctrine had already been skewed, hence the relation in recent 2020 summer protests of discontent in the USA and United Kingdom, and subsequently reinforced as a completion of the cycle at a progressively run University. At the said theatres of undergraduate study, these former secondary pupils would then register for courses such as Gender Studies, Communist driven subject matters, and classes on Race Theory. Upon graduation as Bachelor's degree holders, they would, at this juncture, influence society as a majority within the professions above. This cycle's recommencing would then be initiated via their treasures, (offspring) once commencing their respective educational journeys, through this myriad of the very same ultra-socialist classes and restructured ordained teaching ethics. It is clear within the datum; suffice to say that global governments that have consent from the governed, have indeed displayed a lack of empathy toward their future school-aged generation.

Point 1. From many studies, there is little or no evidence that racism is prominent within western states and was voiced by the black electorate in the recent US presidential election, in fact, Covid-19, Healthcare and the Economy were notable policies cited. This was illustrated by this statement in a recent book Racism and antiRacism in the World: before and after 1945; it is written: Nineteen-forty-five was a global tipping point. Instead of nations being routinely racist, they were to be anti-racist. Hundreds of years of laissez faire attitudes toward discrimination that permeated all six inhabited continents was officially ending. America was at the fore of this new anti-racist zeitgeist in 1945 and it remains at the fore of the 20\% of nations from Europe, North America and Oceania that are committed to anti-racism. These nations have shown how extraordinarily complex it is to end discriminatory practices rooted in history and perpetuated at home, communities, and generally in society. Brush, K. (2020).

Point 2. The effects over the years, whereby left-leaning indoctrinated alumni via their former professors has had a profound prominent antithesis on our natural ways of cultural existence. These said graduates have maturated into parents. In the United States some young children are now being subjected of a debate on their very own gender from as young as 4 years old. The very same parents are introducing "Puberty Blockers" to delay their development. Who makes this decision for young children who are unaware of gender dysphoria? This is not an isolated case, in fact, it has become more widespread. Many have written on this issue and question this change within our child's education at a young age. "The escalating debate has revealed a gap in global laws, pitting family and religious groups against trans activists for legal rulings on whether the decision to transition is up to the child, parents or doctor." Greenhalgh, H. (2020). Additionally, to the previous article, there have been attempts to bring Gender Identity into Kindergartens. Case-in-point being the liberal state of California, a reporter writes: It would be a mild understatement to say this is controversial. Religious 
conservatives fought this, as one might expect. But one does not have to be a religious conservative to wonder if this is not a misplaced policy that says more about adults' ideology than children's needs (Olsen, H., 2019). However, this form of heinous addendum has not been only consigned to the US, it has been additionally propagandised by native-speaking teachers within foreign countries.

Point 3. Over a hundred universities received monetary gifts, contracts, or both from sources in mainland China over a six-year period, according to a Bloomberg article from its analysis inclusive of data from the US government. Top of the mentioned list was Harvard University, which had amassed \$93.7 million, secondary, was the University of Southern California and tertiary was the University of Pennsylvania. It has been reported that China was playing a greater role in U.S. campus life, The PRC was reported to be the largest contributor in that following Qatar at $\$ 1.8$ billion and the U.K. at \$1.1 billion. It is also reported within this article that China accounts for one-third of the 1.1 million foreign students, according to data from 2018-19 compiled by the Institute of International Education. Additionally, it is stated that schools have been looking to global sources to fill seats and find cash in the face of government cuts. The aforementioned is inclusive of the arrest of a Harvard chemistry professor accused of lying about his connections to China and concealing payments to him from a Chinese university. Furthermore, the other universities cited were Stanford and NYU. (Lorin \& Kochkodin, 2020). To this day, there are over 150,000 Chinese students currently studying in the United States. Prior to COVID-19, the UK was during a Chinese student invasion, in fact, the UK's Guardian Newspaper wrote: The figures underline the sector's reliance on tuition income from overseas students. Since 2014-15 the number of Chinese students enrolled in the UK has risen from about 89,500 to more than 120,300. Adams, R. (2020). As the UK is a country of socialism following successive Labour Party governments since the 1970s, culminating in Tony Blair, Britain has been a friendly adversary to China, whereby Chinese money supersedes UK security protocols at liberal leaning universities' enrolments.

Point 4. It is no accident that our children are being prepared for a "Fourth Estate' narrative, to merely be trained/indoctrinated, in readiness for the acceptance of this cultural re-engineering, within our respective societies. Think about it, if this totalitarianism comes to pass or fruition globally, prospective alternative prime ministers, presidents, mayors, and governors, would not be elected to office -by the people. As currently shown and experienced, political one-sidedness of our respective communes have complete dominance: Social Media, Major Newspapers, Hollywood, Talk Shows, Celebrities, Search Engines and for the last 30+ years; been involved covertly with the Education of our youth. No wonder, Orwellian entities such as China, is rubbing its hands with glee. As a consequence, there will be only one sole outcome, world domination of all societies, without a single shot being fired, nor a missile launched, as the conditioning of our youth would have been achieved, with neither resentment nor protest.

Delimitations. The parameters within this research were to merely use the data, which has already been defined, in the public gaze, and still within the framework of international debate, however:

$>$ Data which has not been included, are citations pertaining to in rhetorical nature that is still been litigated within both national and international jurisprudence and racism guidelines. Thus, the above literature will not be included in any statistical nature of this draft.

$>$ The main aim of the data used is a comparison of educational reforms and current practice within teaching theatres. Simply put; an analysis of why there are nations of similar demography and economics with an additional historic reference which blends past to the present philosophies attributed to this paper.

$>$ The procedures and methods included statistical questionnaires and direct scholastic/journalistic inquiry via face-to-face interviews (Direct Engagement). It is attributed to both the political and legal/political sensitivities of the issues portrayed in this study, inclusive of the author's geographical residency.

\section{Results and Discussion}

Quantitative. If the author of this paper was to be permitted to revisit slavery and how it is indulged by educators supporting the non-Caucasian argument of historical slavery, citing the epoch from 1525 to 1866 , the research acknowledges that there is more to it than just Black Atlantic bondage. If we peer into the fact's rationale, we must include all variables within this barbaric trade, including its history and present-day practices. It is on record that 12.5 million African slaves were put to sea to the New World and only 107 million survived this harrowing journey. If we were to peer into the annals of global history, including race/ethnicity and what is occurring today, it would duly provide a more empirical resource, for what has transpired in world slavery. It would negate therefore, the bias and ambiguous history taught in today's western classrooms to our children - at a very young age. Therefore, they would be presented with the absolute truth at school, rather than being subjected to ill-versed unproven political rhetoric, moreover, unsubstantiated or non-inclusive of all data for the entire story of the slave trade. The data represented below discusses the slavery discussion, which has been biased toward non-white slaves in western school systems and being used as a platform via 
the usage of vague selective historical references without taking into consideration the citing of the entire history for the subject of slavery, which was inclusive of forcibly taken individuals who were forced into bondage by ethnicity.

Table 3. True Data of the History of World Slavery (Units Per Million)

\begin{tabular}{|c|c|c|c|c|c|c|c|c|c|c|c|}
\hline Year & Ethnicity & Totals & Sources & Year & Ethnicity & Totals & Sources & Year & Ethnicity & Totals & Sources \\
\hline $\begin{array}{l}1525- \\
1866\end{array}$ & $\begin{array}{l}\text { Black - } \\
\text { African }\end{array}$ & $\begin{array}{c}12.5 \mathrm{~m}, \\
10.7 \mathrm{~m} \\
\text { Survived } \\
\text { Atlantic } \\
\text { Crossing }\end{array}$ & $\begin{array}{l}\text { West } \\
\text { Africa }\end{array}$ & $\begin{array}{l}1530- \\
1780\end{array}$ & $\begin{array}{l}\text { Caucasian } \\
\text { European }\end{array}$ & $1.25 \mathrm{~m}$ & $\begin{array}{l}\text { Italy, } \\
\text { Greece, } \\
\text { Ireland, } \\
\text { UK, } \\
\text { Iceland }\end{array}$ & 2020 & All & $30.0 \mathrm{~m}$ & Global \\
\hline
\end{tabular}

Source: Davis, R.C. (2003) \& The World Counts Organization (2020)

Referring to Table 3. and Figure 1. overleaf, it is shown that the three eras of the slave trade, have not been consigned to history for one race of people - as it is depicted in the western school classrooms. The myth of the white slave owners and their stock of African slaves in bondage presented into our children's minds, are shown to be not only, politically ideological, but negligent to a vital and needed profession. It is clearly viewed from the data introduced, that the reading materials assigned by both English and History Teachers to our treasures, are in a word -misleading, additionally, its misinformation, consequently damaging to the ethos of educational practice.

History of the Slave Trade Revealed

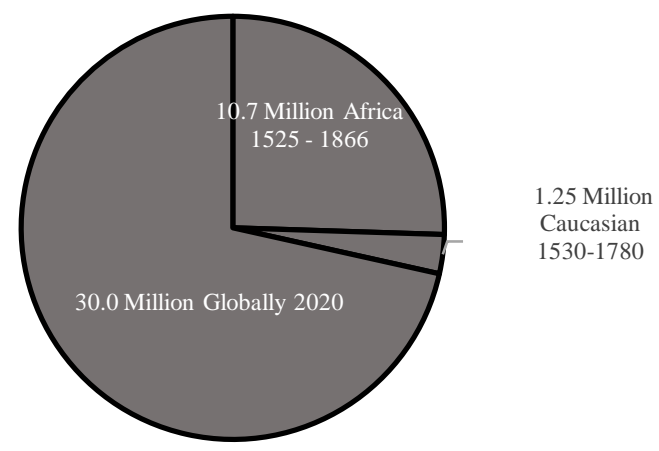

Figure 2. The Segments Over Time -Decerns that Five-Hundred Years Have Indeed Illustrate the Past to the Present

Note: All has been tabulated in the unit of per million

Source: Table 3

To extrapolate this data even further, we can deduce that there is an attempt to recreate history itself in the twenty-first century, but shamelessly in front of our school-aged children, by this teaching method of the omission of key facts, and seeing the collection of convenient data variables to push forward a given radical educator's narrative. That the Caucasian race of individuals is indeed the sole arbiters of slavery upon a nonCaucasian body of people in history, even though, being devoid of the citational facts, is still presented as a lesson in class regularly. According to Tables 1 and 2 (pp.6/7), the only books on slavery are attributed to only the non-Caucasian race and the Atlantic Slavery Trade. How is this so? Suffice to say that of these, 10.7 million of whom survived the perilous journey from West Africa were distributed throughout the Americas, not only the current United States of America. There has been no evidence of the other two illustrations of historical slavery in our school classrooms of the West. Why have not 1.25 million white slaves from the Mediterranean and further north of Europe during 1530-1780 been mentioned in the classrooms? Additionally, we ought to include the current 30,000,000 people originating from all over the world, presently, in enforced captivity? These include all ethnicities; it is now entitled "Modern Day Slavery" - yet once more, why has this form of actual twenty-first-century barbarity under classroom tables, but not in the reading materials? At least to address a balance to subjects taught therein. As a result of this "school infection", you the reader as parents, ought to be more astute in a school's curricula and the reading materials assigned to the pupils.

Qualitative. If we were to delineate why a University body of students has become far more left politically leaning, inclusive of being more activist, we ought to decern the faculty members in a progressive university and investigate what is occurring in western institutions? Below, Table 4, sourced by Dunn, J., and Shields, J. (2016) "Passing on the Right" Professoriate Table. 
Table 4. Professoriate Levels by Political Leaning: Conservative Faculty at a Progressive University, (\%)

\begin{tabular}{|c|c|c|c|c|c|c|c|}
\hline \multirow{2}{*}{ Majors } & \multicolumn{3}{|c|}{ Smith and Others } & \multicolumn{3}{c|}{ Gross and Simmons } & Rothman \& Lichter \\
\cline { 2 - 8 } & (Rep) & (Ind) & (Dem) & (Rep) & (Ind) & (Dem) & Conservative \\
\hline Economics & 33 & 33 & 33 & 29 & 37 & 34 & 27 \\
\hline Political Science & 16 & 36 & 48 & 06 & 44 & 50 & 02 \\
\hline Philosophy & 10 & 30 & 60 & $\ldots \ldots$ & $\ldots \ldots$ & $\ldots \ldots$ & 04 \\
\hline History & 08 & 29 & 63 & 04 & 17 & 79 & 03 \\
\hline Literature & 06 & 21 & 74 & 02 & 47 & 51 & 08 \\
\hline Sociology & 03 & 26 & 72 & 06 & 45 & 49 & 07 \\
\hline
\end{tabular}

Key: (Rep) - Conservatives, (Ind) - Independents, (Dem) - Democrats (Liberals or Further Left)

Source: Jon Shields and Joshua Dunn, "Passing on the Right": Conservative Professors in the "Progressive University (Oxford University Press, 2016): Stanley Rothman and S. Robert Lichter, The Vanishing Conservative - Is There a Glass Ceiling?" in Robert Maranto, Richard Redding, and Frederick Hess, eds., The Political Correct University: Problems, Scope, and reforms (AEI Press, 2009), p.66.

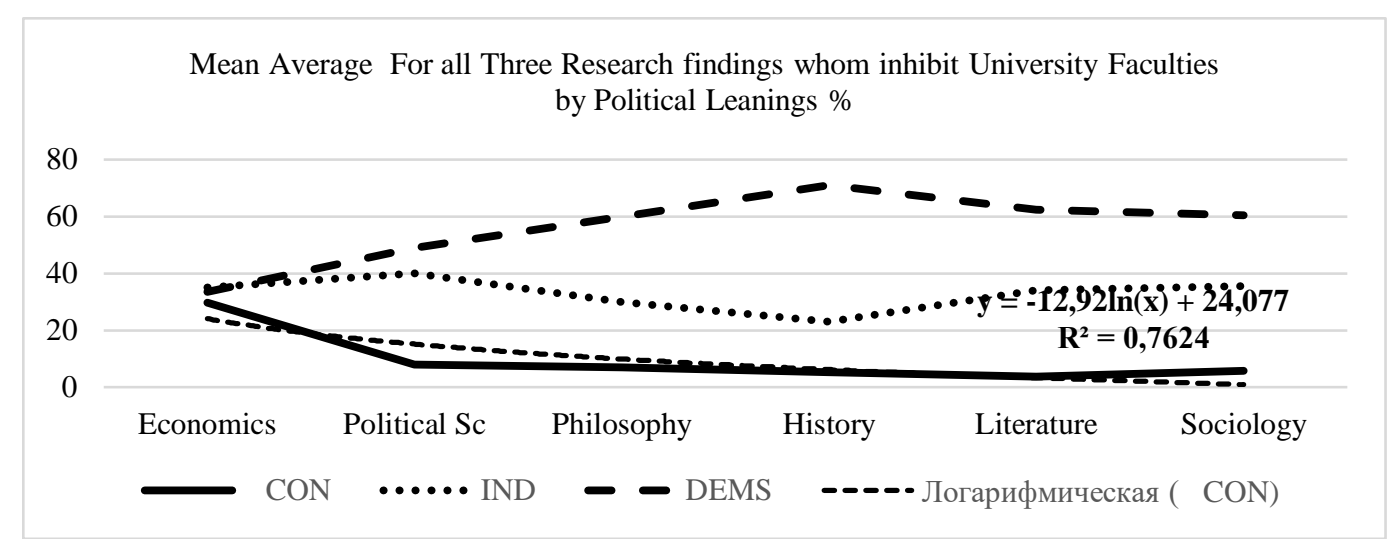

Figure 3. The Divisions between University Faculty Members with Political Affiliations Related to the Majors Taught Source: Table 4

The chart in Figure 3 indicates that there is a significant disparity in conservative professors teaching at predominantly so-called progressive institutions of higher Education via these three comprehensive studies detailed from the data imported from Table 4. p.20 (Shields, J. et al., 2016). The only primary subject that seems faculty balanced is Economics; however, within the liberal arts subjects, only $5.94 \%$ is afforded to the Conservative-leaning faculty members than the $66.6 \%$ percentile of Democratic professors. As we have seen, this is a considerable disparity of imbalance for students at those university campuses cited. Nevertheless, Democratic attributed faculty outnumber Conservatives by a factor of 11 to 1 . We must assume and ask a valuable question: How could students ever be balanced philosophically, in the debate, with the creativity of thought and the decimation of data presented to them? Within coherence, this imbalance in teaching personnel to a student body on any given campus is academically unacceptable. One returns to the original issue, are the students lectured on what to learn rather than how to learn? One feels it is beyond the realm of possibility, or, the logic that any student could be academically balanced, in which an overwhelming left-in-perspective faculty presides over them in the lecture auditorium. These students, therefore, could be our future journalists, teachers, lawyers, but could never be military officers or other positions of authority within the realms of leadership. How could they decern rules or military codes of conduct? Besides, as progressivism is tantamount to passivism or being controlled without leadership skills, this begs the question, how on earth could our treasures survive any discord or conflict scenarios in the future? As both academics/scientists or parents, you ought to investigate and challenge these progressive campuses to see if the courses conflict with your family's traditions, albeit religious, cultural upbringing and morals within your ethical values. I fear from the data that 11 to 1 majority of any given political leaning body of faculty members is bordering on totalitarianism and absolute control in a student's learning framework with an additional enforced grading policy conducive to the political spectrum majority. This enormity within the faculty members' division has led to student activist campuses, owing to this imbalance. It could have happened by successive socialist country governments within public policy - especially ministries of education and media control elements. Moreover, the administrators of both K-12 schools and the deliberate hiring mandates by the social-oriented department heads at western universities. Below Figure 4 is an exemplification of the biasness within the faculties of journalism and for student teachers inclusive of four major core subjects. 


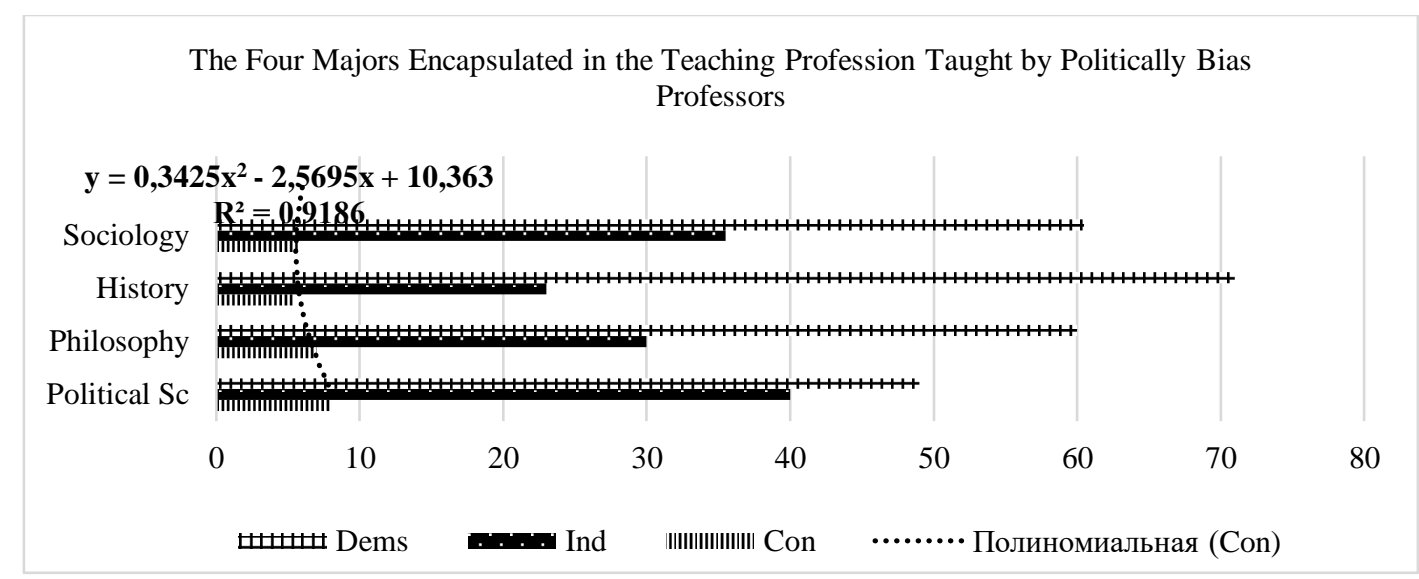

Figure 4. Sampling Mean of Faculty with Confirmed Political Affiliations to whom Trainee Teachers and Journalism Students Receive their Instruction at a Progressive University in \% Terms

Source: Table 4

\section{Scientific Discussion 1}

Within these pages, we will extrapolate the data from Table 5 below and to deep dive into the data analysis required for empirical data mining to expose the seriousness of today's child exposure to ideological classroom teachers and whence they came.

Table 5. The Mean per Subject Major Combination

\begin{tabular}{|c|c|c|c|}
\hline Mean: Faculty Teaching Faculty Totals per Subject Major at University for [Con - Bias] & Disparity in \% \\
\hline Subject Majors & Conservative Faculty & Democrat Faculty & Con: 11.4 \\
\hline Sociology & 07 & 61 & Con: 8.4 \\
\hline History & 06 & 71 & Con: 11.7 \\
\hline Philosophy & 07 & 60 & Con: 16.3 \\
\hline Political Science & 08 & 49 & (Con: 11.7$)$ \\
\hline Mean Totals $=$ & $(07)$ & $(60)$ & \\
\hline
\end{tabular}

Note: Con = Conservative Faculty Members

Source: Smith \& Others, Gross \& Simmons + Rothman \& Lichter (2016)

Goethe once wrote: All theory is gray, my friend. But forever, green is the tree of life, first performed in Faust Part I, (1809). It is clear from the table above that we can delineate the grey from the green. The eradication or the recreation of history within high school subjects is being furthered in higher education theatres by a neoliberal movement that has been growing since the late 1980s in recent terms. The disparity, as illustrated in Table.5, has determined a mean average of $88.3 \%$ faculty advantage compared to the meager $11.7 \%$ represented by conservative professors. What does this mean to both the parents of our treasures? These four majors were chosen to be commensurate with future school teaching graduates that would be unleashed onto our children from 4th Grade. K-12 education is experiencing, as mentioned previously, pp.6/7, lesson shaming upon students of non-color, and for the history which has spanned two centuries. The table analysis coherently depicts the overwhelming democratic leaning faculty from a $\sim$ 4:1 to 5:1 ratio than conservative lecturers. The numbers facilitate the realm of imagination, whereby undergraduate students are predominantly dominated by ideological bias strategies related to Antonio Gramsci's strategy, p.9 to fill the universities to manipulate a balanced clarity of intellectual freedom of expression and balancing of debate inclusive of lecture methodology. It can be seen that the $8.4 \%$ of conservative representation in the subject of history seeds a coercive danger for our children within schools in this subject matter, and therefore, open to educator manipulation and biasness. Finally, from the values notated from 2016, one suspects the neo-liberal advantage could be even higher in 2020. Nevertheless, within the facets of academic research, these results display a considerable divide between the two faculty political leanings for progressive universities, deliberately venturing into a grey area of majority rule in the West. This analysis suggests that all schools within K-12, validating new teachers entering their classrooms and the profession to seek any radical political affiliation, can be done via collating their college histories to perceive any future imbalance of future teaching practice, planning and methodology therein. Therefore, parents ought to be more observant about their child's core curriculum at a given school to evaluate the mindset of their respective home teachers. Reading Materials in core subjects as History, Civics, Business Studies and Literature. It would be an invaluable guide or resource for any parent to envisage a school's overall administrative vision. 
Delineation III. If we were to refer to the 2016 Pisa School Performance results per nation, we would not be a surprise to view that many countries have surpassed the West about high school science studies. Awaiting the updated table in the next few months to be announced:

Table 6. Top Twenty Countries that Scored the Highest for Science

\begin{tabular}{|l|l|l|l|l|}
\hline 1.Singapore & 5. Finland & 9. China (HK) & 13. Slovenia & 17. Netherlands \\
\hline 2. Japan & 6. China (Macao) & 10. China (Mainland) & 14. Australia & 18. Switzerland \\
\hline 3. Estonia & 7. Canada & 11. South Korea & 15. UK & 19. Ireland \\
\hline 4. Taiwan & 8. Vietnam & 12. New Zealand & 16. Germany & 20. Belgium \\
\hline
\end{tabular}

Source: "A Tale of Two Continents" by Pisa via the BBC Reporter Coughlan, S. (2016)

As noted and visible, Western countries represent only 33\%; however, the domination is attributed to South East Asia. The West is only scaled in the lower half of this Pisa (2016) tabulations. Besides, both in Reading and Mathematics subject values are also dominated by Asian countries. The USA is not even on this list. In fact: The USA's politicization and the introduction of "No Child Left Behind" although well-intentioned, has been a dismal failure, MLA (2013).

Data Analysis: (SD) Standard Error of the Difference in Data. Given a statistical property known as the central limit theorem, we know that, regardless of the distribution of the parameter in the population, the distribution of these means, referred to as the sampling distribution, approaches a normal distribution with mean and standard deviation confuse the standard deviation and the standard error, possibly because the names are similar, or because the standard deviation is used in the calculation of the standard error. However, they are not quite the same, and readers (and researchers) must know the difference between the two to use them appropriately and report them correctly, Biau, J. (2011). Therefore, SEM-SD was used for the arithmetic tool within the following process.

$$
\begin{aligned}
& S E D=\sqrt{S E 1^{2}+S E 2^{2}} \\
& S E m=\frac{S D}{\sqrt{N-1}} \\
& S D=\frac{\sqrt{\sum_{X}^{2}}}{N}
\end{aligned}
$$

All data is calculated within a comparison between Democratic University Faculty and Conservative Faculty members: the disparity on the conservative teacher imbalance to the Democrats. Therefore, the Standard Error of the Difference results is from the raw data acquired from last two columns to the right in Table 5. The control grouping is divided into Conservative and Democrat values as the control model and the proposed experimental group. The unit of measure is defined as individual faculty numbers. Arithmetic's for Standard Error of the Difference: from the mean of the biased four majors taught at progressive universities. Data from Table 5 illustrated in Figure 4, p.38. Thus, Omitting Independent faculty values. Averages tabulated between Conservative and Democrat Professors.

Table 6. (SEM) - (SD) Standard Error of the Difference

\begin{tabular}{|c|c|c|c|c|c|}
\hline Democrat =N & $\boldsymbol{x}^{\mathbf{2}}$ & Variables & Conservative $=\mathbf{N}$ & $\boldsymbol{x}^{\mathbf{2}}$ & Variables \\
\hline 61 & 3721 & $\mathrm{~N}=4$ & 07 & 49 & $\mathrm{~N}$ \\
\hline 71 & 5041 & $M^{1}=14763$ & 06 & 36 & $M^{2}$ \\
$=198$ \\
\hline 60 & 3600 & $\sum_{X} 2=60.25$ & 07 & 49 & $\sum_{X} 2=7.00$ \\
\hline 49 & 2401 & $\mathrm{SD}=7.79$ & 08 & 64 & $\mathrm{SD}=7.79$ \\
\hline 241 & 14763 & $S E m 1=4.502$ & 28 & 198 & SEm $=0.4086$ \\
\hline
\end{tabular}

Source: Table 5. Four Biased Majors. p. 38 Computations

Dem: $M_{1}=\frac{\sum x}{n}=\frac{241}{04}=60.25$ Con: $M_{2}=\frac{\sum x}{n}=\frac{28}{04}=7.00$

Dem: $\mathrm{SD}=\frac{\sqrt{\sum_{X^{2}}}}{N}-M^{1}=\frac{\sqrt{60.25}}{04}-14763.00=\sqrt{3690.75-3630.06}=\sqrt{60.69}=\underline{7.79}$

Con: $\mathrm{SD}=\frac{\sqrt{\sum_{X} 2}}{N}-M^{2}=\frac{\sqrt{7.00}}{04}-198.00=\sqrt{49.50-49.00}=\sqrt{ } 0.50=\underline{0.707}$

Data correlated SD - Conservatives (Con) is correlated to Democrats (Dem) then $S D=\frac{7.79}{0.707}=11.02$

Dem: $S E m 1=\frac{S D}{\sqrt{N-1}}=\frac{7.79}{\sqrt{4-1}}=\frac{7.79}{\sqrt{3}}=\frac{7.79}{1.73}=\underline{4.502}$

Con: $S E m 2=\frac{S D}{\sqrt{N-1}}=\frac{0.707}{\sqrt{4-1}}=\frac{0.707}{\sqrt{3}}=\frac{0.707}{1.73}=0.4086$ 
The data correlated within the error; Conservative is correlated to Democrat then $S E m=\frac{0.4086}{4.502}=\underline{0.90}$

Dem - Con $=S E D=\sqrt{S E 1^{2}+S E 2^{2}}=\sqrt{4.502^{2}+0.4086^{2}}=\sqrt{20.268+0.1669}=\sqrt{20.435}=4.520$

Resulting data recorded above clearly illustrates that Democrat leaning faculty has a distinct advantage over the Conservatives when it comes to progressive faculty dominance as the standard difference calculations suggest.

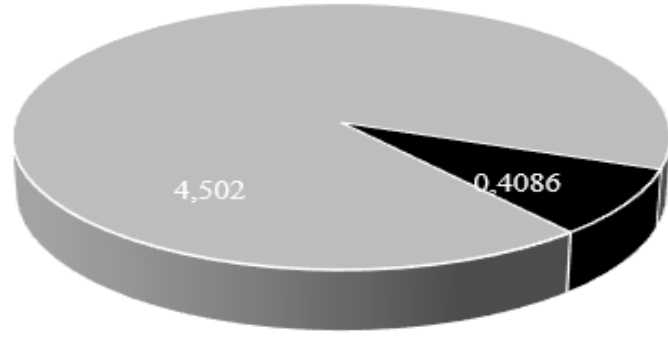

- Democrat Leaning

- Conservative leaning

Figure 5. Standard Error of Deviation of Faculty Members within a Progressive Theatre

Source: Standard Deviation and Standard Error. Biau, J. (2011)

The Deviation is immense in the University polarity sphere. This pie chart clearly illustrates a significant disbursement Pattern between the democratic leaning faculty and the conservatives, by at least a ratio of 11/1, or the Conservatives retain only 9.09\% in a progressive university teaching faculty. The Graphic below (Fig.7), illustrates profound domination in faculty numbers suggesting bias in Teacher Recruitment via its administration, whereby a left-leaning student body would indeed be the outcome.

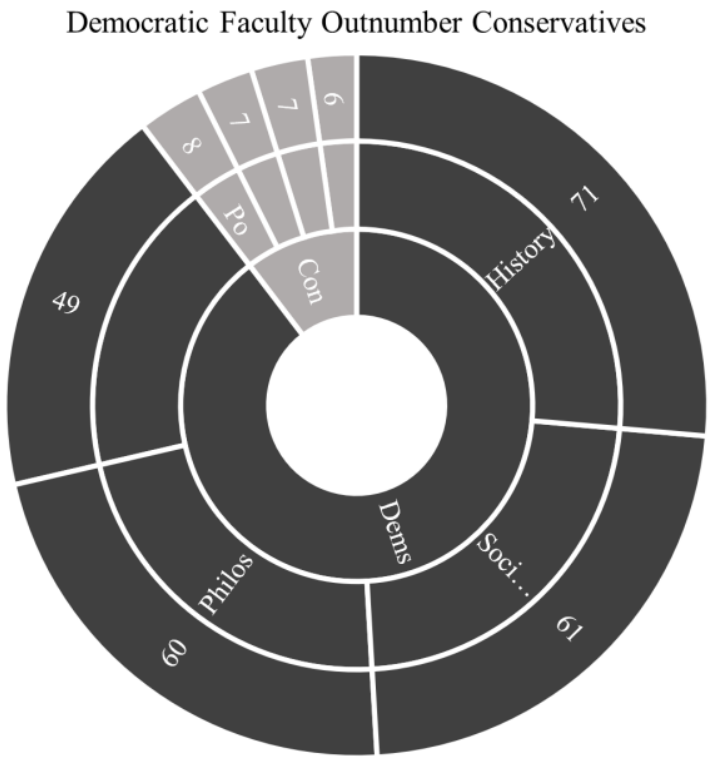

Figure 6. Standard Error of Deviation of Faculty Members within a Progressive Theatre

Source: Table 5

\section{Conclusion and Discussion of the Statistics of Left-leaning Faculty Ramifications}

This ideological manifestation of the teaching method within schools to universities has already come to fruition. Alma Mater from neo-liberal dominated universities is already practicing within the schools presiding over your children in the class. Others have moved into journalism, where the vicious rhetoric is more important than the proven truth. Even worse, they are moving into professorial roles exploiting their students with their scientifically unproven lectures, thus recycling the process yet again as referred to in Figure 1. It is 
since they know they can conduct this egregious practice without any dissent from management, as they are of the same political spurious ideological school of thought. The military requires that discipline to do the unthinkable; politics requires the skill to get someone else to do the impossible for you. The latter has been adopted by neo-Marxism-orientated educators since the late 1980s, culminating in the educators being the proverbial foot soldiers for politicians as are journalists. A further tactic has been the initiation of STEM education. Enticing out treasures to negate the letter A for the Arts; instead of the use of STEAM would be a more appropriate approach to school tooling. Within the first stages of this paper, it was clearly notated that irrespective of Europe having 2\% of Non- Caucasian people and the USA having a mere 13\% in its population, why have the black narratives or histories been taught to school children from the fourth grade onwards?

By reading the Black Slavery in the school classroom, teachers are displaying ignorance toward the history of the indigenous culture per esempio, the United Kingdom, ignoring its traditions brought forward from its ancestry. If we were to be told to learn to forget our respective histories, what would have been the outcome? Would Mongolians accept being told to forget Genghis Khan and Mongol conquests in the 13th and 14th Centuries? Turkey to ignore both the Ottoman Empire from 1299 to 1922? Additionally, ignore the life of Mustafa Kemal Ataturk; inclusive of the lives lost in Canakkale in the first world war, to be consigned to dust. Moreover, the 1200 years of the Roman Empire, The Greek Civilization be forgotten by the world; The Socratic Method for higher education and research, the Anglo Saxons of Britain including the sacrifice given by their forefathers in two world wars and the others that preceded them. Are we indeed to forget world innovation and scientific discovery? Sir Francis Bacon's Empirical Method? Furthermore, are we forced to neglect the destructive forces of the Atom Bombs that had struck Hiroshima and Nagasaki? Or finally, do we allow our treasures minds to be filled with rhetorical insignificance and be accepting of the F.D. Roosevelt's maxim, of collecting the races, genders, sexes, sexual orientation and preference for the centralization of Government. You the reader, decern the potential ramifications for yourself.

The data has also shown that noticeably, the countries cited for receiving such politically charged dystopian teachers in the past two decades have namely been Turkey, Middle East, Mongolia, Italy, Spain, Northern Cyprus, Egypt, Vietnam and Cambodia. Secondly, nations such as Hungary, Poland, Japan and South Korea have strong cultures and have robust traditions, including their enforcement. The said nations have a low tolerance threshold for cultural change and especially in forms of Neo-Marxist rhetoric. This infamy's origins were an infamous school of left-leaning intellectual thought from Europe a long time ago. In fact: The Frankfurt School, known more appropriately as Critical Theory, is a philosophical and sociological movement spread across many universities worldwide. It was originally located at the Institute for Social Research (Institut für Sozialforschung), an attached institute at the Goethe University in Frankfurt, Germany. The Institute was founded in 1923 thanks to a donation by Felix Weil to develop Marxist studies in Germany. After 1933, the Nazis forced its closure, and the Institute was moved to the United States, where it found hospitality at Columbia University in New York City, Corradetti, C. (2016), cited above, it is stated as this movement as defined as 'is' not was. Our children's future? Well, most millennials (from testing) cannot conduct an actual civilized debate, hold a discussion, accept other people's criticism. They are ashamed of being non-black, embarrassed about their parenting, ashamed of being married into one's own culture, comprehending rational thought, and accepting the capitalist ethic. Do these lobotomized graduates wish to work, or are they from affluent families? The "Weather Underground" operated in the 1960s and 1970s described themselves as activists and Left Radical intellectuals. There is nothing intellectual by being domestic terrorists - in which they were classified. If this group's narrative had been ignored, they would have used more explosives and incite rioting on the streets to push this irrational thought process; sounds familiar? This organization's leadership were both white and were majority from wealthy families. Yet once more, is relative to the present and the 2020 Summer of protest: Destruction of Buildings and violence: US, France, Germany and UK unnecessary discontentment, and additionally, insurgence of pro-democracy groups.

Table 7. Sampling Questionnaire/Checks for Prospective Educators to Balance Faculty

\begin{tabular}{|c|c|}
\hline \multicolumn{2}{|c|}{$\begin{array}{c}\text { Teaching Practitioner Vetting Practice Application Form Submission \& Questioning } \\
\text { All conducted via the Ministries of Education Prior to School Interviews \& Appointments }\end{array}$} \\
\hline School Children Teachers K-12 & University Faculty Members \\
\hline University Graduated? - Department Check & University Graduated? - Department Check \\
\hline Teaching Philosophy? & Teaching philosophy? \\
\hline Political Leaning? & Political Leaning? \\
\hline University Department Check Politically & University Department Check Politically \\
\hline Criminal Record Check + Activism Record & Criminal Record Check + Activism Record \\
\hline Probationary Period for (1 Year) & Probationary Period for (1 Semester) \\
\hline Favourite Authors? & Favourite Authors? \\
\hline Parental Check: Occupations? & Parental Check: Occupations?
\end{tabular}


Table 7 (cont.). Sampling Questionnaire/Checks for Prospective Educators to Balance Faculty

\begin{tabular}{|c|c|}
\hline If Post Grad: Thesis Check: Subject Matter & All Papers \& Published and Drafted \\
\hline Whose/was their Role Model? & Whose/was their Role Model? \\
\hline Check if teaching frame is non-biased? & Check if lecturing frame is non-biased? \\
\hline Check Countries of Origin \& State & Check Countries of Origin \& State \\
\hline
\end{tabular}

Note: A database of all staff be implemented to cross-section both School and H.E. Educators to show a balanced ratio based upon $33 \%$ Moderate Liberals 33\% Independent and 33\% for Conservatives

Source: Compiled by the author

Table 7 illustrates the need for specific information to be elicited from a potential educator. Being a teacher is a vocation and in need of its Hippocratic Oath. We are dealing with young, influential, sensitive and suggestive minds. Political rhetoric should not be included in K-12 education or any theatre of learning. Civics education ought to be revamped, so there is no ambiguity within pupils' mindsets. As educators, we must be peers for valid and rational reasons, whereby a trust factor for both pupils and the parents is vital within societal trust development. A child's character building is also an educator's duty in both K-12 and at university. Even an English language teacher is a representative of his or her nation on foreign soil; therefore, an educator is a guest of that school and its nation and must conduct him or herself professionally, appropriately, and within the bounds of ethics.

Teacher Performance and Professionalism Issues. Upon conducting occasional one-to-one interviews for this study numbering 825 within three continents over 5 years, the aspects of western teaching behaviour in the workplace, the following, and repetitive viewpoints were articulated. The teachers cited for criticism by indigenous department heads from Turkey, China (Mainland), China (Hong Kong), and Mongolia were from the UK, USA, South Africa, Australia, Canada, and below 45. Only native teachers' forenames/first names were elicited:

Tardiness.

Unclear oral/diction abilities.

$>$ Lack of attention during lesson planning/preparation and poor teamwork.

> Spelling/Syntax errors in the English Language inclusive of poor grammar usage.

$>$ Over confidence and a feeling of superiority among his/her foreign co-workers.

$>20 \%$ stated alcohol issues with native teachers.

$>$ Being absent for meetings and workshops.

$>$ University: Plagiarism practices observed, no original work produced for classes.

$>$ Refusal of voicing professional viewpoints within management malpractice.

$>$ Merely working for salary inclinations.

$>$ Students not professionally counselled within a course.

$>$ A lack of self-awareness, hence self-evaluation.

$>$ Possession of profound arrogance whilst being inexperienced.

$>$ Office arguments have ensued as these younger western teachers reject criticism.

$>$ Researched only from social media.

$>$ Lack of discipline within classroom management.

$>$ Lack of specific school report drafting.

D Result: Leading to school patrons deciding on teacher practice and lesson delivery.

Parental Recommendation. All parents must check the teachers, including the school's administration apparatus, as they hire the teachers and possess a mission statement. Online lessons are observed if suspecting misconduct. From the outset of reviewing a school, the teacher's credentials ought to be viewed, including the syllabus's validation reading materials and subject contents be appropriate to both you and your child. A teacher's Alma Mata could signal their political loyalties and, therefore, methodology within the classroom. A radical narrative could be easily exposed via the textbooks and literature review topics, especially if they bear no relation to your country's culture and traditions or be anti your culture or religious point of view. In short, this narrative could be a form of hidden propaganda to affect change in your society via the students taught, as its delivery system. It goes for Sex Education and Religious Studies. A child's homework must be scrutinized on every occasion once the teacher has assigned it. The aforementioned is apropos to a pupil's enhancing their goal objectives and intellectual development, inclusive of character-building verification, with all parents being responsible and vigilant. A teacher's attire for duty must follow school guidelines, ministry protocols; if not, this could be a sign of rebelliousness toward peering and a status quo rejection, a common trait for leftleaning educators. It is a more straightforward process for the Universities; the faculties themselves are usually biased by $88 \%$ of a certain politique. Deans, Chairs and senior professors follow the same narrative. It is usually implemented within the auditoria. Any faculty and departments that is/are represented by over $60 \%$ 
ideologically is usually left-leaning. Besides, if a university has a huge political directional leaning, likely, the administration is too, including the President and university's endowment. Books and Academic Paper publications written by your chosen faculty member should be checked to visualize if he/she is of your intellectual taste.

This study has unearthed societal indoctrination within our schools and universities that adversely have been irradicating society norms at a rapidly increasing rate since the late 1980s inception point. Commensurately, there is evidence of systematic brainwashing of the student and pupil bodies -especially in the United Kingdom, Canada, Turkey, Mongolia and the United States of America. While drafting this paper, the most disturbing element is the countless accounts of where grade four pupils are being subjected to classroom teacher manipulation of both history and civics within a given social context. Furthermore, this has been a deliberate strategy on par with the previously cited Critical Race Theory mechanism. If we were to revisit the origins of these Neo-Marxist teaching foot soldiers, it has been portrayed that educators from progressive universities in the West are a clear and present danger to our future generations, societal traditions, and its retention within a society of stability, as they indeed practice in many countries - notated previously. If this irrational, fascistic and Maoist ideology were to continue, we as individual nations would have experienced the erosion of religious liberty, freedom of intellectual thought and expression, law and order, and the removal of sovereign state borders or frontiers. These manifestations above are not a potential outcome but a reality of societal peril to come. Conversely, in one's research, a child is the first and the most suggestible member of our society. As this authoritarian attempt to control our lives within a child's education, it is, therefore, a trial for anti-utopian philosophy. That said, it is fictional no more. If you were to gaze upon the canvas of a Mota Motero painting named "Dystopia", you would then comprehend the extent of the mind of a child following the completion of his/her school radicalization. The work of art described on the Saatchi Art website describes this abstract painting as follows: Dystopian societies appear in many fictional works and artistic representations, particularly in stories set in the future. Therefore, children are the second tenant for control of society. It has been named in this attempt to change society as the Eight Dominions to Dystopianism:

> First: Assign Loans to Nation States rendering them to debt. (Economic Control).

$>$ Second: Indoctrination of our Treasures/Youth engendering passivity and being both-intentionally suggestive and subservient in the future.

Third: News Propaganda; the Press \& Social Media Addiction (One-way Media Control).

- Fourth: To negate Religious Doctrine \& Removal of fire arms (Control by the State).

Fifth: Populational Micro Chipping to control populous Identity, Travel \& Banking.

Sixth: The dissolution of sovereign borders to initiate Global Sectors of those dissolved.

> Seventh: Birth control policy to reduce population numbers worldwide.

> Eighth: Centralization of Government: Educational, Economic, Welfare and Health.

As recounted in this study, the issues within our education system and mental child abuse being enforced by teaching practitioners are notated in the list as the second. Given that this unfortunate war on society from within continues, the future remains bleak. Regaling freedom of expression or speech, this is highlighted in the fifth tenant; that if we were to be outspokenly pertaining any leader of government and a public policy, the microchip could be deactivated as punishment; we would lose our identity, access to banking funds, and the ability to travel think carefully of inserting this form of technology. We must recall, The USA is a multicultural country; only the 574 recognized Indian Tribes on reservations are indigenous to this land. The United Kingdom, consequently, has already become a socialist country and yet multicultural via successive Labour Governments emanating from the 1970s to Blairism in the 1990s. London's original community is now the minority; the so-called "White Flight" had begun over a decade ago. The USA was created upon immigration; Britain was not. Apart from left-leaning rhetoric being currently professed in both schools and universities in the UK, this country of socialism is veering toward China to replicate its policies. Case-in-point being population surveillance, a single person could be photographed over 200 times in one shopping spree. Both additionally and regrettably, Section 5 of the Police Act can impose a fine of $£ 90$ if a citizen were to cover or obscure their face. It is due to the intense face recognition systems adopted by a UK Police State. Thus, if one wishes to peer through a lens into your respective nation's future under socialism, the UK is an obvious example, with the addition, of course -hate speech. There lay the model for the loss of freedom of expression. The 2020 Covid-19 crisis has shown the realization of this attempt of societal control; total lockdowns have been ineffective, but isolated families without salaries for the significant part, and children's detaching from their education. It is an attempt of more instability for the social interaction of our treasures. Moreover, remote learning has been a tool or a nihilist mechanism for their teachers to impart ideological, incredulous, politicized viewpoints. Parents have caught them in the act by their monitoring of "Zoom" classes. A school pupil or University student of the present is forced to follow a Marxist cum Maoist narrative to pass their respective 
courses. This pressure is commensurate to Antonio Gramsci's p.9 model of faculty manipulation or attempted reset of the academic masses within a given nation's society inclusive of György Lukács's philosophy of political correctness with the removal of parental identity. All that has gone before within this academic drafting, plus the sampling of evidence presented, has confirmed the attempt of a social change organization that has unfortunately metastasized throughout the education industry. The former is the antithesis of our upbringing within our respective nations' vested interest by our parents and ancestry alike. It is both a parents' and educators 'moral duty to raise our treasures within carefully constructed guidance in morality and to maturation.

Schooling with Covid-19: Why are our treasures being subjected to a year of dumbing down of the population? Covid-19 or SARS-CoV-2, part of the orthocoronavirinae sub-family, has been used as a weapon to control the population's freedoms, including children's in-person school attendance. $80 \%$ of Deaths in the US from Covid-19 are connected to patients over 80 years of age or people with severe underlying medical conditions. Children account for an only weekly high of 0.7 per 100,000 ; trend test, $\mathrm{p}<0.001$ for fatalities Adigun, A. (2020), so, what is occurring within both national and regional leadership? This Chinese pandemic has been a welcomed tool for a more radical leaning control base, as a control mechanism of the global populous, as it has been its original intent, for nearly a century. As parents, educators within an academic premise, must decern, within the dictum of our children's future well-being: is there an Orwellian mechanism, to facilitate the future preparation of subservience and submissiveness, within our global community by the using of our treasures? Alas, this covert dumbing down process in our children's classrooms or zoom virtual learning environment, is to prepare future leaders, decision makers and voters, for a Marxist or Maoist viewpoint, thus, be eventually gullible citizens. To prove this fact, as this is a body of scientific research, if we were to visit the latest pupils' report cards, according to a recent study by Fairfax Public schools: Office of Research and Strategic Improvement USA, for November 2020 - STUDY OF TEACHING AND LEARNING DURING THE COVID 19 PANDEMIC, the Analyses of Q1 Secondary Marks, Table 2. p.3, entitled: "Percentages of All FCPS Students with Marks of F in 2 or More Classes, Overall and By Student Group, SY 2019-20 Q1 Compared to SY 2020-21 Q1". The findings were astonishing, however, unsurprising to all the global teaching profession. Table 2. had illustrated the following: All Middle School and High School Students showed an F increase of $+300 \%$, White pupils $+200 \%$, Black $+200 \%$, Asian students' failing grades had increased by $300 \%$. Students with disabilities had a failure increase of $+400 \%$, whereby English Learners FGrades had risen by $383 \%$ and Economically Disadvantaged students had increased Fs at $+375 \%$. The report additionally tabulated gender failure results: in fact, males had increased in F-Grades by a rate of $+233 \%$ and much worse for females who attained an increase in Fs by $+600 \%$ In addition, many other US States have been cited for depreciating school pupil's grades. One would ask the readers, why are our children being forced out of school, even though, the W.H.O. shows no evidence that children are in fact, in danger, as they have the strongest immune systems. Moreover, this does not preclude the rise in student suicide rates. The British medical Journal in conjunction with the British Psychological journal published research on this very subject matter. It concluded that following a sampling of 3077 individuals on three occasions, from March to May (2020), "The study found that the proportion of respondents reporting that on at least one day in the previous week they had wanted to end their life increased from $8.2 \%$ to $9.2 \%$ and then to $9.8 \%$, over the three waves of the study. These rates were highest in young adults (aged 18-29), rising from $12.5 \%$ to $14.4 \%$ throughout the three waves. The authors note that direct comparisons cannot be made but that this past week rate is higher than an $11 \%$ past year suicidal ideation rate reported by young adults in another pre-covid-19 study. (BMJ, 2020). In conclusion, it has been recorded that liberal-leaning school districts, school governors and socialist states, have been the sole arbiters to a continued school lockdown, with unsubstantiated scientific evidence, and more importantly, the dangers it represents.

What is really Fascism in today's Western Society? To define the noun fascism, we must view the meaning attributed to the Oxford Learner's Dictionary. There is one's students approach for lexical guidance: / fæJizəm/ [uncountable] (also Fascism) an extreme right-wing political system or attitude that is in favour of the strong central government, aggressively promoting your country or race above others, and that does not allow any opposition. As Oxford University U.K., has become a left-leaning institution, it is without astonishment they have included adjectives and adverbs such as "extreme" and "aggressively" within their definition inclusive of Right-Wing. In fact, in history, Fascism had no political bias, just merely a system of political activism. Secondly, a compounded version from the same sourcing above "(disapproving) extreme views or practices that try to make other people think and behave in the same way" Here, there is no political affiliation within the compounded meaning. Opinion: should a general dictionary, or lexicon, opine personal political opinion within its indices of definitions? Within the remit of citation, if we were to review a publication written in 1979 referring to Austrian fascistic intellectual thought, Führerprinzip or leadership principles stated in Bruce F. Pauley's paper The Austrian Example discerned that: The fascists had little difficulty in the deciding what 
they were against, "Marxism" parliamentarians, individualism, and often, but not always Judaism, (Pauley, 1979). An assertion of the present day's democratic left-leaned protagonists suggests that they have taken on the mantle of their notions of Fascism. If the truth be known, research has displayed that following the atrocities of the Third Reich in WWII, the then U.S. Democratic party of whom were in previous constant contact with Adolf Hitler, then decided to both remove the fascist mandate related to his misgivings from its policies, and to transfer this stain to the Republican Party/Conservatives, as a matter of pronounced ideological policy.

Revisiting historical fact once more, suffice it to say, the authors cited that President Roosevelt's democratic administration had indeed assisted the German war effort in World War Two. It is exemplified within the excerpts from FDR vs. Hitler (Freidel, F., 1987 \& The Coca Cola Company under the Nazis Jones, E., and Ritzmann, F.) that the U.S. government had been supplying Hitler's nation during the period above. Oil produced by Standard Oil is a case in point. One may be wondering why the previous data is credible to this paper's research subject's representation, especially toward fascism, and related to this study's thesis? It has been shown that the U.S. Democratic Party had never removed itself from fascism. It could be debated that the party has left the fascistic policy angle; however, it has not deleted this from its vocal and physical activism. A hidden agenda was beginning to be masked following the second world war. Consequently, aspersions directly toward the center's right conservatives is only commonplace, as this was the democratic goal after all. To remove itself from the shame of being connected to Nazi Germany therebefore, and to push a reverse narrative of fascism onto the conservatives. As previously quoted in the Oxford Learners Dictionary, "extreme right-wing political system or attitude that is in favour of strong central government" has confirmed that further left-leaning democrats are indeed in pursuance of a given utopia via fascism. The democratic parties globally of the left have become entities of communism and fascism - a system of economic thought with total control narratives through an individual state. Thus, there is a strong systematic attempt to negate the opposition by shaming, doxing, or applying deliberate falsehoods onto critical, creative thinkers: this ideology's communism aspect. In short, demographically, policies would be controlled by a government, state ownership, for health institutions and education being key in the codification of the present for western society. One-term President Jimmy Carter, [another Democrat] initiated the nationalization of the state-run U.S. Department of Education in October 1979. Coincidence? This paper, inclusive of results, has tried to be non-biased. However, datum has become one-sided, leading to a suggestion that our children are/will be subjected to biased tuition within academies of continued indoctrination. The indication for pupils and students alike from all these said schools, and later, in adulthood, will be displaying this one-way attitude, thinking, philosophy and brainwashing by educators has already come to fruition. We should all pray for the $\mathrm{Z}$ generation and, after that, to readdress this imbalance in today's ever-changing society.

These graduates (as stated within this paper) who became radicalized via progressivism within progressive western academic institutions, prevent by enforcement, being questioned on any subject where they have a particular point of view. So, this begs the question, how on earth did they ever pass classes at university? The only answer is within university practice itself. Consequently, we are going through an evolution of negated freedom of intellectual thought and developing creative ideas within an expression, opening the door to a more controlled indoctrination process throughout the world emanating from the West. The data unambiguously suggests that both school pupils and higher education students are being currently subjected to "What to learn? rather than How to learn?" ardent philosophy, a deliberate misadventure platform tune with a form of misinformation policy by their respective educators. It has been concluded from the datum presented here and from the delineations from those nation's students engaged in overseas studies promotion that a country's promising students will be under ideological and family/traditional national threat once they undergo studies at prominent western universities. Exemplified further, scholarship promotions within countries resembling Turkey, Mongolia and other non-western states are a recruiting ground for globalist organizations and westernized left-leaning institutions. To-date, organizations of whom venture into a developing country to promote scholarships based in the western-oriented universities, take the best students of that given nation, then embark on a course of study within systematic alt-intellectual frameworks. It is currently being conducted online but have the same manipulative narrative faculty, who profess a particular ideology. Upon graduation, these said international students return to their land of birth if they had studied in person to greet their parents. On the same note, the parents would immediately notice the change in their young offspring's demeanour, thought processes within the intellect and, more importantly, minus their original cultural identity. Returning students to Mongolia as an example had changed in persona since acquiring western education. Furthermore, their psychology has digressed from a traditional Mongolian patriotic mindset to a more neo-liberal openminded one. Some of these parents have elucidated that their future generations have since become unrecognizable, especially to their grandparents. These said parents had once great goals for their own children's future. However, the result has been to-date, an anti-original traditionalist culture. 
Secondly, these parents related their child's new behaviour, to a former soviet Mongolia, but more extensive liberal, for their tastes. It was also elucidated that more conflicting issues had been cited: 1) expressive in sexual orientation openness, 2) a lack of patriotism, and 3) disrespecting an original race and their nation's traditions. However, parents have or have had to accept these children's changes due to their financial concerns/constraints and the overall country's economic instability. Having these so-called western narrative propagandists as teachers in foreign international private schools has only exacerbated a nation's cultural transformation; the Republic of Turkey's youth had already been exposed to this nearly three decades ago; therefore, its youth culture has transitioned to open-minded parenting with loosening traditional valued mindsets. Social media has been also a key promoter of weakening values, as their reporting and posting alike are guided to global social transitioning. It is commensurate to the current United Kingdom's transition to socialism and multiculturism, whereby the original post world war two nation has become unrecognizable. Britain is currently beyond recognition, with three socially oriented parties and a society that is disconnected from Anglo-Saxon historic traditions and values devoid of any sense of a notable history of the commonwealth. The United Kingdom is a prime example or model for the effects of consecutive socialist administrations. In short, Brexit came 40 years too late, and Britain lost its adjective "Great" in the late 1960s. One wonders, what would the ancestors of two world campaigns have thought of this destruction of a once a great nation? Do you, the international reader, wish this effect or result upon your respective nation?

\section{Scientific Discussion 2. Global Warming: Preached by Teachers in our schools?}

Why are our children being false fed "Global Warning Narratives" at school? Predetermination of Future Taxes to come, versus the annals of historical record and empirical fact. As ridiculous as it seems, an unknown world thermostat control regulator switch must be hidden from our gaze. Yes, it sounds both amusing, and the above agreement in Paris was indeed a falsehood. (COP 21 Treaty) If you were to read the document thoroughly, you would have found that some nations, namely China and India, do not have to comply with the other states' timelines to adhere to clean-up their respective pollution. Indeed, they do not have to commit to this program until 2030. Homo sapiens are solely responsible for carbon emissions; hence global climate increases and could not be further from the truth. It is rather neoliberalism that has been in league with the Banking community and the others representing the "One Percent" (Global Financial Elite) to initiate a carbon tax, and we are the so-called culprits, paying the price for our respective heaven and earth indiscretions. For a carbon tax to be bestowed upon the world populous, the powers that be must prove empirically, without any doubt, that the human race is iteratively causing these emissions and aiding mother earth's so-called destruction. However, they have none. This mendacious attempt to extort more taxes from the general population will be nugatory without those above proven/empirical evidence being publicly illustrated.

Fact: within empirical method. As an example, we have had at least two recent significant climate changes; "Little Climate Optimum and the "Little Ice Age." The northern hemisphere experienced a warm period of climate called by many the Climate Optimum, which coincided with intense solar activity as the sun's radiation was at its strongest to elucidate further, from 900CE to 1300CE. The weather yielded excellent crops from arable farming and even grapes were being successfully grown in southern England (a rarity) inclusive of being a competitor to French wine sales. It had led to an increased population and the many wonders of Gothic architecture being created. This epoch was not to last. A slow continued cooling began to engulf Europe. The turn of the fourteenth century displayed a cooling over the centuries of $4 \mathrm{c}$ lower in average temperatures. It does not seem much, but to the populous of Europe, it became a disaster. This century had five major storms that were so large in today's comparison that from Italy to Ireland, the storm reached major cells flooding the fields, thus destroying grain harvests year-on-year. Famine had become commonplace, with many succumbing to disease and other forms of pestilence. From 1371-1791, France witnessed 111 famines alone, and 1601, Russia faced a worse famine scenario; half a million of its people lost their lives due to starvation via crop failures. In 1347, a calamitous event occurred throughout Europe; vessels entering ports from Asia were the harbinger of death via a disease called the bubonic plague "Black Death". As the fleas hosted on black rats and was transmitted to weak starving humans, this five-year period attained 25,000,000 fatalities. This cooling period culminated with the year as Gillen D'Arcy Wood wrote "1816, The Year without a Summer" and in his abstract, he wrote: The so-called "Year Without a Summer" - 1816 - belongs to three years of severe climate deterioration of global scope caused by the eruption of Mt. Tambora in Indonesia in April 1815. With plummeting temperatures and disruption to major weather systems, human communities worldwide faced crop failures, epidemic disease, and civil unrest on a catastrophic scale. In cultural terms, the dreary summer of 1816 is best known as the setting for Mary Shelley's writing of Frankenstein, a novel whose iconic creature offers a figure for the millions of hungry and dispossessed of Europe during the protracted climate emergency that followed Tambora's eruption. 
We must question whether carbon emissions were attributed by us as claimed by the IPCC or the globalists. The above statement factors included the $\mathrm{CO} 2$ emissions by the volcano and the sulphur, which rose high into the troposphere and merged with the particles forming a sheet of cloud. It reflected the weakened radiation from the solar minimum event cycle, this had led to a cooling of the northern hemisphere for three years from 1816 and the previous four centuries as the sun had no sunspots denoting a solar minimum, thus, a reversal to the 900-1300 little climate optimum. From permafrost, we can see samples taken by scientists from beyond the deep oceans that have shown these deviations in climate naturally, without human intervention. It is also depicted and documented that we, as the human race, cannot prevent such climatic phenomena, thus were not responsible for its causation. By-the-way, permafrost emits constant methane into the air; however, never disclosed in specific data codification. A further illustration for the refusal of human causality to current global warming is initiated from the past tense as if we were to refer to the twentieth century. The twentieth century had already entered a new warming climatic phase following the Little Ice Age. This warm cycle lasted to around the early 1940s. Following world war two, manufacturing came to the fore and emissions from the factories were intense globally, like the automobile production industry and the economic boom. With the carbon emissions in the air for decades, there was no evidence of global warming; the data confirmed and showed that for several decades after the post-war industrial resurrection, the climate had in fact, cooled until the 1980s. Yet again, this was not a human-made event.

Having read this chapter insofar as collating data to ascertain why globalists are so insistent on the population for being responsible for polluting the earth to destruction. One has tried to provide various scenes through the looking glass of generations to elucidate the IPCC political aspersions' absurdity. Other variables that could counter human-made global warming claims are as follows: If we have our atmosphere that contains Water vapour, Argon Nitrogen, and Oxygen, but the smallest is $0.054 \%$ of carbon dioxide (500 ppm). However, it is the water vapour Greenhouse gases that are the most important, not Carbon Dioxide. The United Nations continually cites that if $\mathrm{CO} 2$ increases, then the earth temperature increases, but what they have failed to mention is the reverse. When there is an increase in periodical temperatures through the ages, this warming produces more Carbon Dioxide. The warmer the oceans produce the most $\mathrm{CO} 2$ emissions on the planet; nothing else comes close to it. If as the politicians and the controlled copious media outlets stipulate that $\mathrm{CO} 2$ drives climate change, it positively does not correlate with the science. We ought to ask ourselves one thing whether $\mathrm{CO} 2$ affects global warming. The climate Forecaster Dr. Piers Corbyn, a climate physicist in the late 1980s, discovered that the more active the sun was, the spots were formed; therefore, the weather would be warmer. Solar activity has always been connected with our climate, he says. If we were to believe in the statement that the sun is responsible for our climate variations, where does politics come into play, and why is human-made global warming a big statement in policy? Politicization went with a newly elected British Prime Minister, Mrs. Margaret Thatcher, in the 1980s. Following many forms of industrial actions that had led to the fall of a previous conservative government. These events turned her against the unions. The coal industry was the main protagonists for industrial disruption and initiated a black-out of electricity in the nineteen-seventies in the United Kingdom. Recalling these events, she crushed the mining strike and weakened any unions who marched against her. Coal mines were closed, and Mrs. Thatcher thought of the carbon emissions she could use against the unions to destroy the planet and causing global warming. Owing to her distrust for the oil industry and its Middle Eastern producers, she explained to Royal Society that there's money on the table for them to investigate human-made carbon dioxide and our effects on global climate rises. It, in effect was the birth of political globalism's venture into human-made international carbon policy.

Subsequently, the left-leaned activists had no more communism to fight for as the wall already had come down in Berlin, so they became the foot-soldiers for this globalist campaign with their Marxist ideals being displayed in other avenues. Billions of dollars were ploughed into research for professors to exploit. With the advent of the press and the media, the process began in earnest. Climate-related sciences rose with the attractive research grants being provided to scientists at universities as long as it involved proving empirically that we were responsible as a global population for warming the planet. Scientist frequently uses mathematical computational graphics models which are so adaptable for manipulation, hence, displaying favourably on the side of global warming. It would guarantee a research paper's publication following its peer review. However, for this research to be highlighted as notable TV coverage, it would have to be a spectacular announcement irrespective if the data were to be falsified or not, such as the world's poles will shift if we do not act to save the planet. Therefore, biased results, which are dramatic for the journals and sensational stories for the media, will only be accepted by the editor via the IPCC countenance. If a professor were to request a research grant for the examination of chimpanzees 'interaction in governments schools, one would most probably be refused, but if one were to add how this could affect global warming, this would be another story and deemed acceptable for funding. A new branch of journalism was spawned. Especially the environmental journalists, if they were to get the story wrong, they would be fired from their positions. Yes, it is as brutal as this. Today, corrupt 
journalism is so much to the fore; it has become commonplace. For instance, an article depicting the breaking off of Ice from Antarctica is as ordinary as leaves falling from a tree in autumn. IPCC's climate scare stories are usually misinformation; it is said that with a small increase in global warming, malaria will move north. It was also remarked that mosquitoes do not survive or thrive at temperatures below $16 \mathrm{c}$ and $18 \mathrm{c}$. As a prominent scientist in this field, Professor Paul Reiter is a professor of medical entomology at the Pasteur Institute in Paris, France, and an adviser to the World Health Organization (WHO) a specialist into mosquitos and the diseases: remarked that malaria is not tropical in the artic they breed. In Russia, in the 1920s, mosquitoes were responsible for thousands of deaths. It dispels the IPCC's myth of the climatic endurance of mosquitos. Many professors have also been noncomplimentary regarding the IPCC's contentious peer-reviewing process. So, it has come to a stage in our lives -especially as academics and for the scientific community at large that if we attack the notion of human-made global warming, the reaction is expected to be a series of death threats, vilifications at the university and finally, the possibility of losing your position in life.

Delineation IV via Empirical Scientific Method - A Real Man of Science and in Climate. To conclude this how this globalist politically human-made carbon emissions falsehood of a policy is forced down our throats, and more predominantly preached to our school pupils on a continued-perpetual basis, allow me to illustrate an example of an observant professor from Denmark. He went through both academic and political tribulations to merely have his research paper published, even though it was one the climatic discoveries of a generation, and how our so-called notable scientists had been treated by the UN when new evidence has been presented to them, countering human involvement in the causes of global warming? Within empirical exemplification, we will cite a scientific study of fortitude, which was initiated by Professor Dr. Henrik Svensmark, a physicist at the Division of Solar System Physics at the Danish National Space Institute (DTU Space) in Copenhagen, Denmark. He is defined online as: known for his theory on the effects of cosmic rays on cloud formation as an indirect cause of global warming. Referenced below, it is this scientific story of perseverance.

We commence with Dr. Svensmark's perspectives for a galaxy that we are not light-years from, but we are indeed a part of. From distant parts of our Milky Way, another variable of our Earth's climate control system could be found. He believed that there were other factors apart from this human causal path to global warming, which was being promoted incessantly by the wrongful politics on planet earth. Therefore, this Danish Space Professor could have only peered at one element of our planet, the sky - more specifically, the clouds, and the mystery of what makes them form in the first place to cover the sky at intervals or cover us like a blanket as we slumber. The question: How do the clouds support global warming and the temperature? Unlike the humanmade creation, we are told to believe. To delineate the Danish professor's work in laymen's terms where possible, the sun has always been a contributing factor for sustaining life on this orb; thus, it would automatically be responsible for our heating and cooling systems via its radiation emissions. Further out into space within our galaxy are four spiral arms in our galaxy formation, these have regions of new stars and some are heavy stars. These often die and create super novae... from this explosion emits subatomic cosmic rays. Many hit the Earth's atmosphere with regularity and hardly mentioned. At the beginning, Svensmark hypothesized that these cosmic rays were responsible for the formation of lower atmosphere clouds, the most essential form of cloud formation. However, if the sun was at its solar maximum and the radiation emissions were at its strongest intensity, then these cosmic rays would be intercepted, and less would penetrate the Earth and fewer clouds would form. If we were to reverse this scenario for a solar minimum, whereby radiation would be less in intensity, this would allow more subatomic cosmic rays to hit the Earth's atmosphere and consequently, more clouds would form, and cooling the planet's surface. Thus, we would receive the picture of Dr. Svensmark's observations. When a star dies out in the far and distant galaxy, a super nova is the result. This explosion propels cosmic rays (subatomic particles) to earth at nearly the speed of light. When falling, they make entry into our atmosphere to collide with the aerosol particles forming a cloud. Yes, not our aerosol emissions as the globalists wish us to believe that are ruining the world, but there are natural aerosol particles in our atmosphere. Lower clouds are formed and produce our rain via the evaporation process within the interaction of our rivers, tributaries, lakes, seas and oceans. However, the formation of clouds in the first instance is the common denominator here. It was the premise to Svensmark's hypothesis and going beyond a theory. Qualitatively he needed to cross-reference the data of periodical cloud formations data from the cosmic ray arrival into our atmosphere, then to correlate these data streams with both the solar minimums and maximums. He completed it and everything matched. The clouds were more abundant via solar minimums, and there was a historical landmark with smaller lower ceiling cloud formations within solar maximums; where the reduced cosmic ray infiltration on the earth was due to the stronger radiation levels from the sun; thus, fewer clouds filled the sky. Hence the climate recorded was indeed warmer. This suggestion by Svensmark was based on a correlation on worldwide cloud cover with the cosmic ray intensity. His speculations were to be as much crucial as $\mathrm{CO} 2$ emissions and solar brightness. It was proof empirically for Dr. Svensmark to finalize the draft for his article to be published and findings shared with the world's academic climatic 
concerned community. He did his rounds of presentations marketing his and team's findings. However, the neo-liberal-leaning politically funded professors from the IPCC brotherhood were very skeptical and did not agree with the cosmic ray hypothesis's findings. To no surprise, the United Nations Framework Convention on Climate Change (UNFCC) ignored his findings. Many scientists challenged Svensmark's thesis, and the stipulations being unrealistic.

Following his paper on the correlation of solar activity with the earth's climates with the cosmic ray particles, had no real substance with the already corrupt or the politically correct version of being "influenced" academe. Svensmark, and his team had to derive an experiment which proved where specifically the subatomic cosmic rays came from within the galaxy and correlate the data with the earth's temperate climate. Conversely, these super novae locations had to be mapped into $\mathrm{H}=$ Hot Earth Climate and $\mathrm{C}=$ Cold Earth Climate. Therefore, when the cosmic rays arrive from a super nova's $\mathrm{C}$ location within the galaxy, then these ray particles would arrive here in the solar maximum, where maximum intensity radiation would deflect ray distribution, hence less clouds would be formed due to less cosmic ray infiltration. This would confirm the cold climate projections as well as hot climate periodicals if the mapping were correct. With higher solar magnetic activity is at its highest less cosmic rays penetrate out magnetic field thus, less clouds are formed; therefore, the earth heats up. Do you still feel that the manipulators of global politics are correct with the notion that $\mathrm{CO} 2$ is responsible for climate increases and we are indeed the cause of this? The conceptualization that the sun was just an unimportant ball of gas and had no real effect on the earth's climate, is well and truly over. Carbon 14 isotopes from cosmic rays are evident on the earth. A thousand years ago, as it was the hot period, even the Vikings could map all of Greenland due to the lack of snow cover. Svensmark denotes: Currently, sixty to seventy percent of the earth is covered by clouds, and as the clouds take their orders from the stars. He realized that the politique was against him, so a new experiment had to be devised. Wheretofore, his findings be vindicated within the study that the formation of cosmic rays to cloud cover proves the original hypothesis. Top geologists knew that there were hothouse and icehouse periods, but they knew it was something to do with the sky, however, it could not be proved. The geologists finally joined their datum with Svensmark's Cosmic ray solar datum, and the correlations matched. The experiment above illustrates how the sun modulates the cosmic rays and the effect on lower cloud formations to define the climates, thus affecting the geological data from a galactic year away.

All the data correlated with the geological, historical, solar and cosmic variants finally proved his hypothesis, even in conjunction with other sciences. This paper and its findings should have been accepted immediately by the editors of the journal within the Royal Society, but it was, rejected on many occasions, and sixteen months later, it was accepted for publication. Yes, this is how difficult it was today for excellent scientists who wish to investigate the causalities of our climate, who care not for political correctness and being bullied by the uneducated. And as an example of political correctness affecting versus empirical data via valid experimentation, being made difficult. He stated: We are a part of the greater universe hence its effect on our climate. It is a known physicist who should have been nominated for the Nobel Prize and already held the Energy-E2 Research Prize and the Knud Hojgaard Anniversary Research Award. For the misguided, misinformed, or both, it is hoped with sincerity, the sections above on the IPCC's deceived notions of us. The human race, being responsible for this so-called global warming, with our carbon emissions and other obdurate legislation brought upon by unsubstantiated cronyism, crosses the line of scientific discovery and its empirical method. Are our undergraduates, as a result, being subjected to unreal theories monopolized by the majority left-leaning collaborative faculty? The IPCC is a globalist controlled political lobbyist entity, as The Council for Foreign Relations, The IMF, The World Bank and The United Nations. Imagine the revenue from a global carbon tax; it will be in the trillions, not billions of US dollars. To scare a population of pending global doom or catastrophe for their carbon emissions irresponsibility is the "Fear" narrative applied to enact this carbon tax globally eventually. To conclude this section, we must only believe in the science and the raw data that is derived from any given study - not politicized for misinformed consent nor a future global economic stratagem. Our children are currently being subjected to participating in global warming causality narratives within a classroom by politically motivated educators whose knowledge is devoid of specific study and its factual conclusions, yet again, to provide a future global population to contribute to another tax that would enrich the $1 \%$ of the already wealthiest corporation on earth, the banking entity that controls and monopolises the whole world.

\section{Concluding Research Findings within Synopsis}

$>$ The legacy of Antonio Gramsci was less of a danger ninety years ago, compared to now.

$>$ School reading materials have become deliberately racially divisive within the politique.

$>$ Our children and their cultures are subjected to an elegy to lament our way of life, for its ending.

$>$ Parents of all nations should now be both aware and vigilant of their treasure's education. 
> Moderate liberals are not involved in the politicization of our schools. In fact, it is attributed to the hardened left-wing elements of western society which retain Marxist and Maoist viewpoints and ideological leanings.

$>$ Radicalization of the teachers emanates from their former alma mater's faculty base.

$>$ The devolution of schools began to emerge from the late 1980s.

$>$ Origination: Frankfurt School, (University of Frankfurt 1930s) - USA, (1933-1960s) - UK (1988) Europe (1990) - Turkey (1996) - Asia (Currently).

$>$ Teacher Training outlets and theories taught suggested to be investigated and reformed.

$>$ Press Associations globally publish articles with anonymous sources to sway influence.

$>$ Educators need to vet more thoroughly to intercept and prevent certain political methods being placed upon our youth.

$>$ In high school examination performances, in Reading, Science, and Mathematics, all these subjects have Asia in the top two positions of the international league tables. In Mathematics alone, there is not one solitary western country in a top five position.

$>$ The Top Universities in the West are conforming to Marxist viewpoints, i.e., from university to university in both the UK and USA, the faculty outnumbers conservatives by $80 \%$ and $90 \%$ compared to $55 \%$ or so in the 1960s. Presently, student teachers are taught within a politicized and socialized ideology, omitting traditional reading course materials. Socratic Method is virtually non-existent. Therefore, parents from overseas countries who are considering sending their children to well-named colleges, think again!

$>$ Contrasting global warming research is being stifled if it does not fit a certain narrative.

$>$ The removal of the acceptance of the science fact replaced by misinformation rhetoric. Dr. Svensmark's research ought to become respected as he has been inconvenienced by not the scientific peers, but by a pernicious global network of left-leaning funded professors.

$>$ A child's parents are not aware of what is occurring within their schools and universities.

$>$ Child abuse does not refer to only the physical, but also to mind and its conditioning.

To be inserted within pertinence, this body of work has shown additionally that education has become a political theatre and scientific research must follow a one-sided political narrative, rather than validating the complete data stream. It is clear without ambiguous rhetoric, that any academic will face or has been faced, with these ideological protagonists in the workplace. If he or she, professor, lecturer, or politically unbiased schoolteacher do not follow a certain narrative, their respective careers could be in the balance. This following the shepherd akin to sheep scenario, and compounded with education and institutions becoming business, has abolished the professional academic work ethic, thus removing the educator from the teacher. This is then passed onto the student body with overworked cum underpaid faculty members, resulting in an unproductive or stultifying class due to fatigue - even worse, with the advent of virtual learning online. The end game, simply put, with all the data notated in this paper, has shown unrelated student reading materials and subject matters, bad teaching practice. The furthering of left-leaning teacher training at prominent Western colleges - inclusive of a dominance of its faculty members, has led to our students' (treasures') radicalization. With unfortunate addition, most school and university administrators, are indeed left-leaning purveyors of stifling work environments devoid of real social management skills. If all the findings were quantified and coagulated, our world the globe encompassing our treasures, could succumb to regulations without substance culminating in the erosion of all sovereign states' meritocracies, history, morals, religions, cuisines, border sovereignty and more importantly, their cultural existence. Neo-liberal "economicus et politique" would then oversee the disinformation and misinformation more than we are currently experiencing today via journalism and educators alike. Not only are our children at stake, but the teaching profession itself. Do we accept a reality from the details provided, for our future generations to become only mere acolytes or surfs akin to the Bolshevik Revolution of 1917? Only then, Antonio Gramsci's dream would have been of tailored significance. Therefore, one begs the question; are we indeed progressing or regressing as a civilization? Revisiting the United States of America, the concluding summary from all the data accumulated, has clearly indicated without reservation that its current political apparatus has been both vilified and invective to one group of its population, beyond any reasonable doubt. From a litany of left-wing unproven, invalid rhetoric and individual state legislation, the traditional conservatives in the past five years, have faced castigation, chastisement, vituperation, calumniation, traducement, defamation, denigration, obloquy, and other forms of endless malicious smears. In addition, the current $45^{\text {th }}$ President has been constantly attacked prior, and during his Oval Office Tenancy. Within one's fifth decade of undulating existence, never has been seen, such foul hatred, been versed toward a sitting US head of state. Within the facts collated thus far within this body of research, if this man were to fail to attain a second term in office, then America's future would be extremely bleak, and the subsequent end of the Republican Party. So much so, that the hidden disloyalty to its leader would be more evident, like the rats leaving the proverbial sinking ship -this would probably occur within a few weeks prior to the end of the President's term in office. This is merely to disassociate themselves from him, thus, saving 
their own necks unnecessarily. From the evidence, this $45^{\text {th }}$ President had certainly chosen the wrong party to be the leader of. His followers over nearly four years, have/are being pushed against the wall. In fact, the actions of the opposition, have been nothing more than an attempt of despotism: Their stultifying rhetoric coupled with their supporters' actions of ignorance toward conservative thought, have been a clear and present danger to the nation in itself: Primarily, Control of the Media, Silicon Valley, [information control] -this paper's disclosures on our treasures' school indoctrination, political correctness, gender issues imposed on children, left-wing groups violence - wilful property destruction - however - unpunished. Secondly, interference with religious freedom and unwarranted state election regulation changes - in light of Covid-19, via an atheist Orwellian Asian state. Consequently, with a possible removal of the incumbent president, and all the malicious tactics being imposed onto the conservative base, the future is indeed very bleak. One would say, there could be a breaking point with traditional conservatives. One would suggest that a mini rebellion could precede an entire insurrection. If this unfortunate episode were to occur, the protestors would be in their rights to overthrow a government, due to the threat to their freedoms and security. We must recall that "people power" would eventually change a nation from within. Exemplified by 2730 BC Set rebellion, Egypt, The French Revolution May 1789 when the Ancient Régime was abolished, Philippines rebels against Spain 18001872, Revolution in the Kingdom of Poland (1905-07), and to The Cedar Revolution, Lebanon 2005 and so on. Our treasures are our existence and a country's future, and if the citizens' security were to be threatened inclusive of future offspring by the Government, therefore, we would refer to "Despotism". As this political divide is realistically irredeemable, we must consult ourselves from within the parameters of existence, to envisage the resulting outcome. A further question to enthuse you; from where does this statement below originate? "But when a long train of abuses and usurpations, pursuing invariably the same Object evinces a design to reduce them under absolute Despotism, it is their right, it is their duty, to throw off such Government, and to provide new Guards for their future security. -Such has been the patient sufferance of these Colonies; and such is now the necessity which constrains them to alter their former Systems of Government."

In fact, this is from the original document written in 1776. "The Declaration of Independence". So, if a tyrannical leadership were subject to an insurrection or rebellion, even the sitting president, could not implement the following as that he/she would be a part of that given tyranny in the first instance. Notable Codes: 10 U.S.C. $\$ \$ 331-335$ Sec. 331: Federal aid for State governments Whenever there is an insurrection in any State against its government, the President may, upon the request of its legislature or of its governor if the legislature cannot be convened, call into Federal service such of the militia of the other States, in the number requested by that State, and use such of the armed forces, as he considers necessary to suppress the insurrection. U.S.C. (1807). 10 U.S. Code \$ 252: Whenever the President considers that unlawful obstructions, combinations, or assemblages, or rebellion against the authority of the United States, make it impracticable to enforce the laws of the United States in any State by the ordinary course of judicial proceedings, he may call into Federal service such of the militia of any State, and use such of the armed forces, as he considers necessary to enforce those laws or to suppress the rebellion. U.S.C. (1807).

From this fifth year of the conducting of this research -in an attempt to inform both parents and the scientific world, if one were to be asked, what could be this forthcoming US general elections [in under a month] outcome? Honestly, with data in-hand, one still could not even utter an answer: metaphorically, scientifically and rationally -as the Republican Party itself, has some members of disloyalty, who sway their policy decisions constantly. Moreover, if this forty-fifth president were to somehow dissolve Section 230 of the Communications Decency Act or 47 U.S.C. § 230, a Provision of the Communication Decency Act which is conjoined to the 1996 Communications Decency Act, (CDA) then the social media platforms and information highway, could be under certain control. Additionally, private publishing companies who have carte blanche in their selection of proposed manuscripts, need to be readdressed in law, of whom have adopted the using of politically correct biasness toward pending authors. The aforementioned suggestions are realistically, nye on impossible, due to the so-called conservative party not paying any attention to the House of Representatives' elections seriously in 2018. This resulting loss to the opposition party, handcuffed the sitting president in lawmaking legislation, and only the party itself was to blame for its own ineptitude. Therefore, an elected US leader, could not implement new bills, and was in fact, having to fight tooth and nail, all the way to the end of his first term of office. If we could reverse time to say 2015 or so, given the demeanour and presentational unorthodoxy of being the $45^{\text {th }}$ Presidential candidate, one would have suggested to him, to form his own independent party which could have had loyal like-minded future senators, inclusive of Congressmen/Congresswomen that possibly could have facilitated their leader with more furtherance. In summation, the United States was always an experiment in progress within multiculturism, and so continues to this day. When this anti-sovereign state notion was enforced onto the United Kingdom, via the very same political correctness in the $1970 \mathrm{~s}$ from successive socialist driven governments, today, the UK is unrecognisable, thus, had surrendered its identity, owing to external left-winged entity interference. To 
conclude this segment, we must question, what is the US suited to in political systems? Should it continue as a Democracy or return to a Republic? It has seemed since the early twentieth century that the nation has suffered the Democracy ideology [assists how a government is run] model, compared to being a Republic which is a pure unambiguous form of government. Having illustrated the dystopian episodes that have been fermented within the US since the 1960s. Empirically following stark reasoning, the $45^{\text {th }}$ president basically exposed the hidden agendas upon Capitol Hill, and how policies were subversively convened. The Republican Party today, has not represented its people in the clear diligent modus, except being polite rather than within decisiveness - which has led to the overthrow of conservatism currently throughout. It has been cited over many epochs, that democratic governments have become socialist states. Conversely, why would a nation have fifty different state laws? Within absurdity, individual states (majority liberal controlled) could do as they please within policy making, hence the resulting systematic disastrous changes earlier this year 2020, to supposedly facilitate this Covid-19 pandemic for the forthcoming election in a few weeks" time. One would ask the American reader; where were the presidential lawyers, when these changes were being considered? Yet, once more, the Republican Party had failed to counteract these states via zero jurisprudence, thus, weakened its leader. It could have been suggested many eras ago, to resemble many other nations globally, and an election be only conducted federally/nationally or mono system or in one legally agreed way, as the future leaders would control the whole country. This would defend both the sanctity and more importantly, the security of the process therein. In summation, this case of the United States, it is clear and evident that multiculturism should not be imposed onto other nations, as the US was built upon it. The evidence suggests strongly that indigenous sovereign states that had ancestors who once fought to defend their entire existence, are now failing in light of politically correct indoctrination. Therefore, have surrendered their sovereign identities, cultures, frontiers, and religious congruence, and consequently, has led to a young unemphatic social media-driven generation.

In summation, one refers you to an epithet an American novelist once wrote, "The world is a fine place and worth the fighting for, and I hate very much to leave it" (Hemingway, E., 1940). One's research into the reengineering of our children within their classrooms, and its possible consequence, suggests that we ought to only countenance the first two parts of this expeditious quote. If the Eight Dominions to Dystopianism ever reveals itself in fruition, we will indeed return to the form if slavery in which this paper had begun, and to revisit the Dark Ages, then consign both ourselves and children to a global form of Slavery in itself. Only then, we would have come full circle within the evolution verses devolution hypothesis. One leaves you with a statement of real pertinence: If the human species is to rise to the full height that is demanded by its dignity, and by its intelligence, we, all of us, move to a situation where that condition is permanent (Hitchens, C., 2009).

Funding. There is no funding for this research.

\section{References}

1. Adams, R. (2020). Third of non-EU university students in UK come from China. More than 120,000 Chinese students enrolled at British universities in 2018-19. The Guardian UK. https://www.theguardian.com/education/2020/jan/16/third-of-non-eu-university.-students-in-uk-comefrom-china. Accessed February 20, 2020.

2. Adigun, A. (2020). ABC News: COVID-19 disease in children is usually mild, fatalities rare, UK study says: The study looked at over 500 children in 20 countries. https://abcnews.go.com/Health/covid-19disease-children-mild-fatalities-rare-uk/story?id=71462424. Accessed November 17, 2020.

3. Adorno, T., and Bernstein, J.M. (1951). Freudian Theory and the Pattern of Fascist Propaganda, in Arato, Andrew and Eike Gebhardt (eds.). The Essential Frankfurt School Reader, Continuum: New York, 1982. Part 1:118-37, Oxford: Blackwell. https://www.taylorfrancis.com/chapters/freudian-theory-patternfascist-propaganda-theodor-adorno-bernstein/10.4324/9780203996065-9. Accessed July 4, 2019.

4. Allen, A. (2020). 20 Picture Books for 2020: Readings to Embrace Race, Provide Solace \& Do Good. https://www.embracerace.org/resources/20-picture-books-for-2020. Accessed May 10, 2020.

5. Archives, N. (1776). Declaration of Independence: A Transcription. The unanimous Declaration of the thirteen United States of America. Congress, July 4, Original Document Transcription. National Archives. Cited: "Despotism". (2 ${ }^{\text {nd }}$ Para). Available at: https://www.archives.gov/founding-docs/declarationtranscript. Accessed March 21, 2017.

6. Beck, G. (2020). How to Talk About Race Packet. Epoch Education. https://roar-assetsauto.rbl.ms/documents/7004/Howtotalkabout\%20race.pdf. Accessed October 12, 2020.

7. Biau, J. (2011). In Brief: Standard Deviation and Standard Error. Orthop Relat Res., 469(9), 2661-2664. doi: 10.1007/s11999-011-1908-9. 
8. BMJ (2020). Covid-19: Suicidal thoughts increased in young adults during lockdown, UK study finds. British Medical Journal, 371. https://www.bmj.com/content/371/bmj.m4095. Accessed November 4, 2020.

9. Cole, M. (2017). Conclusion. In: Critical Race Theory and Education. Marxism and Education. Palgrave Macmillan, New York. https://doi.org/10.1057/978-1-349-95079-9_10. Accessed May 15, 2018.

10.Corradetti, C. (2016). The Frankfurt School and Critical Theory. Internet Encyclopedia of Philosophy and its Authors. ISSN 2161-0002. https://doi.org/10.2307/303230. Accessed February 21, 2017.

11. Coughlan, S. (2016). Pisa tests: Singapore top in global education rankings. BBC News. https://www.bbc.com/news/education-38212070. Accessed May 4, 2018.

12.Couzens, D., and McCarthy, T. (1994). Critical Theory. Oxford: Blackwell, 1994. Business conceptions of sustainable development: a perspective from critical theory. https://doi.org/10.1002/bse.353. Accessed January 10, 2018.

13.Davis, R.C. (2003). Christian Slaves, Muslim Masters: White Slavery in the Mediterranean, the Barbary Coast and Italy, 1500-1800. Palgrave Macmillan; 2003 edition. ISBN-10: ISBN-13: 978-1403945518. Available at: https://www.palgrave.com/gp/book/9780333719664.

14.Freidel, F. (1987). FDR vs. Hitler: American Foreign Policy, 1933-1941. Proceedings of the Massachusetts Historical Society. Third Series, 99, 25-43. Available at: https://www.jstor.org/stable/25080976?seq=1.

15.Higham, C. (1983). Trading with the Enemy: An Exposé of The Nazi-American Money-Plot 1933-1949. http/ibcom.org/library/allied-multinationals-supply-nazi-germany-world-war-2. Accessed November 6, 2019.

16.Fairfax (2020). Study of teaching and learning during the Covid-19 pandemic. Analyses of Q1 Secondary Marks. Fairfax County Public Schools, Office of Research and Strategic Improvement. Percentages of All FCPS Students with Marks of F in 2 or More Classes Overall and By Student Group, SY 2019-20 Q1 $\begin{array}{lllll}\text { Compared } & \text { to } & \text { SY } & \text { Q20-21 }\end{array}$ https://go.boarddocs.com/vsba/fairfax/Board.nsf/files/BVJV847F7247/\%24file/Q1\%20Marks\%20Rpt\%2 0-\%20v6\%20lzh.pdf. Accessed December 2, 2020.

17.Freedman, D. (2013). Why Experts keep failing us - And How to Know When Not to Trust Them Little. Brown and Co., 2010, p.78. ISBN-10: 0316093297, ISBN-13: 978-0316093293. Available at: https://www.littlebrown.com/titles/david-h-freedman/wrong/9780316087919/.

18. Horowitz, D., and Laksin, J. (2019). How Radical Professors at America's top colleges indoctrinate students and undermine our democracy. Mar 10, 2009. ISBN 9780307452566. https://www.abebooks.com/9780307452559/One-Party-Classroom-Radical-Professors-Americas0307452557/plp. Accessed May 13, 2018.

19.Jaschik, S. (2016). More Educated, More Liberal. Inside Hired. https://www.insidehighered.com/news/2016/04/27/study-finds-those-graduate-education-are-far-moreliberal-peers. Accessed June 20, 2018.

20.Higham, C. (1983). Trading with the Enemy: An Exposé of The Nazi-American Money-Plot 1933-1949 by This is followed by "The Coca Cola Company under the Nazis" by Eleanor Jones and Florian Ritzmann; From the "Coca Cola Goes to War"). The Coca Cola Company under the Nazis. Available at: https://libcom.org/files/How\%20the\%20Allied\%20multinationals\%20supplied\%20Nazi\%20Germany\%2 0throughout\%20World\%20War\%20II.pdf.

21.Knopp, S. (2011). Union Teachers Explain How to Push Marxism in the Classroom. 18/04/2011 a Los Angeles teacher's union leader (in the Tax the Rich shirt) and Megan Behrent a New York City teacher affiliated with the International Socialist Organization, explain how to push Marxism in the public-school classroom. https://www.youtube.com/watch?v=dDeXhmTz0M. Accessed March 6, 2012.

22.Lewis, C.S., O'Flaherty, W. and Root, J. (2018). Education without values, as useful as it is, seems rather to make man a more clever devil. The MISQUOTABLE C.S. Lewis. What He Did not say, What He Actually said and Why it Matters. ISBN: 9781532638428. Available at: https://ru.scribd.com/book/399745096/The-Misquotable-C-S-Lewis-What-He-Didn-t-Say-What-HeActually-Said-and-Why-It-Matters.

23.Lorin, J., and Kochkodin, B. (2020). Harvard Leads U.S. Colleges That Received \$1 Billion From China. Bloomberg Business. Available at: https://www.bloomberg.com/news/articles/2020-02-06/harvard-leadsu-s-colleges-that-received-1-billion-from-china.

24.Lovell. J. (2019). The west has assumed that Maoism, like Soviet communism, has been left in the dust: no European rebels these days carry a Little Red Book. But the ideology is resurgent in China and remains hugely influential elsewhere. The Guardian. https://www.theguardian.com/books/2019/mar/16/onwardmarch- maoism-julia-lovell. Accessed July 6, 2020. 
25.Lukács, G. (1968). History and Class Consciousness, Cambridge Mass.: MIT Press, [1968], 1971. ISBN: 9780262620208. 408 p. November 1972. Available at: https://mitpress.mit.edu/books/history-and-classconsciousness.

26.Olsen, H. (2019). California wants to teach kindergartners about gender identity. Seriously. Columnist and a Senior fellow at the U.S. Ethics and Public Policy Centre. Available at: https://www.washingtonpost.com/opinions/2019/05/13/california-wants-teach-kindergartners-aboutgender-identity-seriously/.

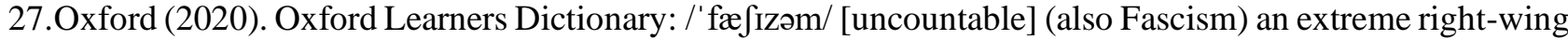
political system or attitude that is in favour of strong central government https://www.oxfordlearnersdictionaries.com/definition/english/fascism\#. Accessed October 10, 2020.

28. Marcuse, H. (1955). Eros and Civilization. (Beacon Press) ISDN: 0-8070-1555-5. Available at: https://www.lehmanns.de/shop/geisteswissenschaften/1285712-9780807015551-eros-and-civilization. Accessed June 23, 2019.

29.MLA (2013). Why is USA so low in international education league tables? https://molletacademy.com/2013/03/13/why-is-usa-so-low-in-international-education-league-tables/. Accessed November 14, 2015.

30.Pauley, B. (1979). Fascism and the Führerprinzip: The Austrian Example. Central European History, 12(3), 272-296. Cambridge University Press. Available at: https://www.jstor.org/stable/4545869? seq=1.

31.Saatchi, Art. (2020). Dystopia 003 Painting by Mota Motero. Saatchi Art Digest. https://www.saatchiart.com/art/Painting-Dystopia-003/76443/4928583/view. Accessed November 22, 2020.

32.Sandbrook, D. (2020). Baying mobs, fallen statues and vandals no better than Chairman Mao's cultural' wreckers. https://www.dailymail.co.uk/debate/article-8400875/DOMINIC-SANDBROOK-Baying-mobsvandals-no-better-Chairman-Maos-cultural-wreckers.html. Accessed July 20, 2020.

33.Shields, J., and Dunn, J. (2016). Passing on the Right: Conservative Professors in the Progressive University (Oxford University Press, 2016). Print publication date: 2016 Print ISBN-13: 9780199863051. Published to Oxford Scholarship Online: March 2016. Available at: https://oxford.universitypressscholarship.com/view/10.1093/. Accessed March 11, 2019.

34.Spencer, I. (2016). Self-Identifying Marxist Professors Outnumber Conservatives as College Professors. https://www.academia.org/self-identifying-marxist-professors-outnumber-conservatives-as-collegeprofessors/. Accessed October 23, 2019.

35.Svensmark, H., and Calder, C. (2008). The Chilling Stars: A Cosmic View of Climate Change. Edition 2, Illustrated, reprint. Icon Books. (268 pages) ISBN 1840468661, 9781840468663. Available at: http://news.bbc.co.uk/2/hi/programmes/newsnight/6362407.stm. Accessed December 13, 2020.

36.The World Counts (2020). Slavery Still Exists. https://www.theworldcounts.com/stories/Modern_Day_Slavery_Statistics. Accessed October 16, 2020.

37.Tkachuk, T. (2020). Establishment of the Nazi regime in Germany and the position of American politics and diplomacy. Available at: http://www.americanstudies.history.knu.ua/en/archive/10-2/2020-10-tkachuk/.

38. Whitehouse, D. (2013). Global Warmings and Fatal Deceit. Global Warming Policy Foundation https://www.cato.org/publications/commentary/global-warmings-fatal-conceit. Accessed March 23, 2017.

39.10 U.S.C. Insurrection Act of 1807. Code:10 U.S.C. $\S \S 331-335$ Sec. 331: Federal aid for State governments. Available at: https://www.govinfo.gov/content/pkg/USCODE-2010-title10/pdf/USCODE2010-title10-subtitleA-partI-chap15.pdf. Accessed March 4, 2018.

40.10 U.S. Code $\S 252$. Whenever the President considers that unlawful obstructions. Cornell University. Available at: https://www.law.cornell.edu/uscode/text/10/252. Accessed: March 4, 2018. 